\title{
AN EXAMINATION OF COMPETING VERSIONS OF THE PERSON-ENVIRONMENT FIT APPROACH TO STRESS
}

\author{
JEFFREY R. EDWARDS \\ University of Michigan
}

\begin{abstract}
This study examined two versions of the person-environment (P-E) fit approach to stress, one representing the fit between environmental supplies and employee values (S-V fit), and another the fit between environmental demands and employee abilities (D-A fit). Hypotheses based on three competing models derived from the P-E fit literature were tested with a procedure that overcomes problems with the measurement and analysis of fit. Results indicated that the relationships of S-V and D-A fit with strain combined aspects of the models with other relationships suggested by P-E fit theory and the organizational stress literature. Also, S-V fit was linked primarily to dissatisfaction and D-A fit to tension, but both versions were related to both forms of strain.
\end{abstract}

The concept of person-environment (P-E) fit is widespread in organizational behavior research. In essence, P-E fit embodies the premise that attitudes, behavior, and other individual-level outcomes result not from the person or environment separately, but rather from the relationship between the two (Lewin, 1951; Murray, 1938; Pervin, 1989). This basic premise underlies theories in various domains of organizational behavior, such as job satisfaction (Dawis \& Lofquist, 1984; Locke, 1976), job design (Hackman \& Oldham, 1980; Kulik, Oldham, \& Hackman, 1987), individual power (House, 1988), organizational climate (Joyce, Slocum, \& Von Glinow, 1982), employee selection (Schneider \& Schmitt, 1992), career choice (Holland, 1985; Schein, 1978), organizational entry (Chatman, 1989; Wanous, 1980), and the quality of work life (Rice, McFarlin, Hunt, \& Near, 1985).

The concept of P-E fit is particularly prominent in organizational stress (OS) research (Edwards \& Cooper, 1990; Eulberg, Weekley, \& Bhagat, 1988; French, Caplan, \& Harrison, 1982). This prominence is largely due to the conceptual advantages of the P-E fit approach over alternative approaches, most notably in which stress is viewed as a condition or event in a given situation (Cooper \& Marshall, 1976; Hall \& Mansfield, 1971; Matteson \& Ivancevich, 1979) or as a psychophysiological response of a focal person (Ivancevich \& Matteson, 1980; Parker \& DeCotiis, 1983; Selye, 1956). Situa-

The author thanks Susan J. Ashford, Richard P. Bagozzi, Cary L. Cooper, Jane E. Dutton, and three anonymous reviewers for their helpful comments on an earlier version of this article. 
tional approaches are flawed because they overlook individual differences in how situations are cognitively appraised, whereas response approaches fail to capture variation in the psychological meaning of situations that yield the same response (Lazarus \& Folkman, 1984; McGrath, 1970). The P-E fit approach avoids these problems by representing cognitive appraisal as the subjective comparison of person to environment and by distinguishing this comparison process from its outcomes (e.g., French et al., 1982).

Despite these conceptual advantages, research into the P-E fit approach to stress presents several dilemmas. First, although P-E fit is useful as a general paradigm, it actually encompasses two distinct versions of fit, one in which stress is viewed as a misfit between the values of a person and the environmental supplies available to fulfill those values (S-V fit; Cummings \& Cooper, 1979; Edwards, 1992; French et al., 1982; Schuler, 1980) and another in which stress is depicted as environmental demands that tax or exceed the abilities of the person (D-A fit; French et al., 1982; McGrath, 1976; Sells, 1970; Shirom, 1982). Debates regarding the relative conceptual merits of S-V and D-A fit have yet to be resolved (Harrison, 1978; Shirom, 1982), in part because of an absence of studies comparing S-V and D-A fit within the same taxonomic domain-that is, holding constant the dimension along which fit is assessed (Caplan, 1987). Without these comparative studies, it is unclear which version of fit should guide theory development and empirical inquiry. Second, authors have proposed various functional forms relating PE fit to strain, defined as impaired psychological and physiological wellbeing (Harrison, 1978; Kulka, 1979), but few conceptual criteria have been derived to predict a priori which form will emerge in a given study. Moreover, only a handful of studies have tested more than one functional form (e.g., French et al., 1982), making it unclear which form best depicts the relationship between fit and strain. Third, studies of P-E fit are plagued with methodological problems that render their results largely inconclusive (Edwards, 1991; Edwards \& Cooper, 1990). Thus, it is unclear whether the P-E fit approach itself is empirically justified, let alone which version or functional form is most strongly related to strain.

The purpose of this article is to compare the supplies-values and demands-abilities versions of the person-environment fit approach to stress and to test different functional forms relating both versions of fit to strain. This article contributes to the P-E fit literature in several ways. First, it weighs the conceptual merits of S-V and D-A fit, derives predictions as to which version is more strongly related to strain, and empirically compares both versions within the same taxonomic domain. Second, it examines the psychological processes underlying S-V and D-A fit to predict specific functional forms relating both versions of fit to strain. Third, it avoids methodological problems with previous P-E fit research, most notably those resulting from the use of difference scores, by adopting the polynomial regression procedure developed in my earlier research (Edwards, 1994; Edwards \& Parry, 1993). 


\section{MAJOR VERSIONS OF THE PERSON-ENVIRONMENT FIT APPROACH TO STRESS}

\section{Supplies-Values (S-V) Fit}

As indicated earlier, S-V fit refers to the match between a person's values and the environmental supplies available to fulfill those values. In this context, values represent conscious desires held by the person (Edwards \& Cooper, 1990; French et al., 1982; Locke, 1976) and thus encompass preferences, interests, motives, and goals (Cummings \& Cooper, 1979; Edwards, 1992; Schuler, 1980). Supplies refer to the amount, frequency, and quality of environmental attributes that may fulfill the person's values (French et al., 1982). Although supplies can be conceived as either objective or subjective (French et al., 1982), only subjective deviations of supplies from values influence strain (Edwards, 1992; Schuler, 1980). Thus, the core process underlying $\mathrm{S}-\mathrm{V}$ fit is the cognitive comparison of the perceived and desired amount, frequency, or quality of conditions or events experienced by the person.

Most theories based on $\mathrm{S}-\mathrm{V}$ fit contain the proposition that strain increases as supplies fall short of values (Cummings \& Cooper, 1979; French et al., 1982; Schuler, 1980), but they are equivocal as to the effects of excess supplies. One approach to resolving this ambiguity is to consider the effects of excess supplies on a given dimension of S-V fit over time and on related dimensions of S-V fit (Harrison, 1978). This approach allows identification of four distinct processes. Two processes denote that excess supplies will further reduce strain. The first, here labeled conservation, occurs when excess supplies are retained to satisfy the focal value at a later time; accumulated sick leave or surplus income saved for future expenses are examples. The second, carryover, indicates that excess supplies on one value may help fulfill other values. This situation may occur for supplies that are instrumentally related, as when excess autonomy enables a person to bring about desired changes at work, or for supplies that have a symbolic character, as when promotion beyond one's aspirations signifies status and accomplishment. Both conservation and carryover yield a monotonic relationship between S-V fit and strain, so that strain decreases as supplies increase toward values and continues to decrease as supplies exceed values (see Figure 1a). ${ }^{1}$

The remaining two processes indicate that excess supplies increase strain. The first, labeled depletion, occurs when excess supplies hinder the future fulfillment of values on the focal dimension. For example, excess support from a supervisor on a given occasion may preclude support from him or her at a later occasion. The second, interference, signifies that excess

${ }^{1}$ Technically, the term monotonic applies to relationships that continuously increase or decrease and thus would include asymptotic relationships (see Figures 1c and 1d). However, this term is used here in a more restrictive sense, meaning relationships with a constant slope (i.e., Figures 1a and 1b). Although these relationships may be more precisely termed linear, this term is reserved for regression equations that use only first-order environment and person measures as predictors. 


\section{Two-Dimensional Version of Monotonic Model for S-V Fit}

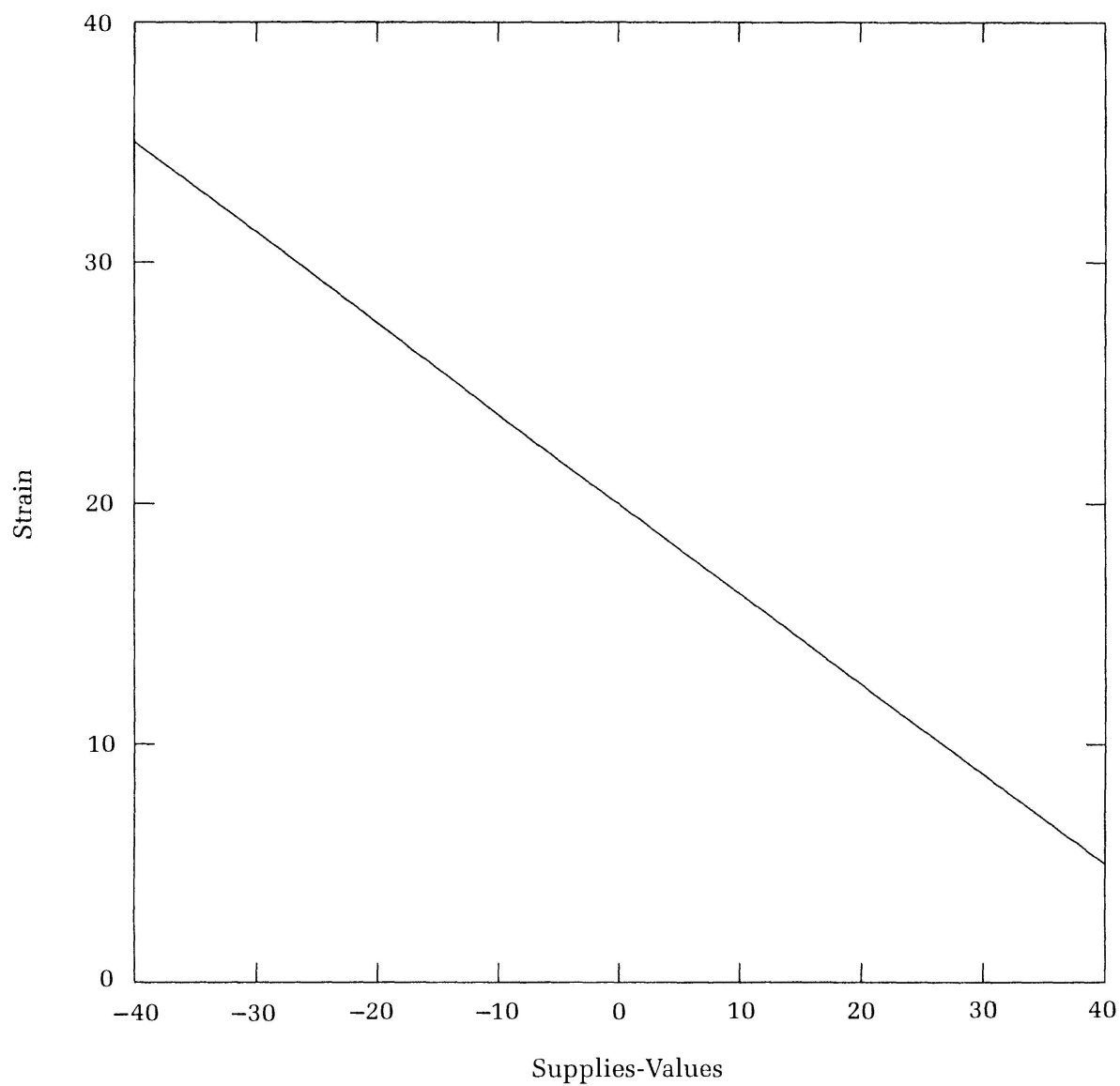

supplies on one dimension inhibit value filfillment on other dimensions. This may occur when excess challenge hinders an individual's desire to obtain a sense of proficiency, or when excess contact with co-workers inhibits his or her desire for privacy (Harrison, 1978). Both of these processes yield a curvilinear relationship with strain (Figure 1e) that is such that perfect $\mathrm{S}-\mathrm{V}$ fit is optimal (yields minimum strain).

When excess supplies do not influence future fit on the focal dimension or affect $\mathrm{S}-\mathrm{V}$ fit on other dimensions, the relationship between supplies and strain will be essentially flat (Figure 1c). Examples of such supplies include job security, medical benefits, and working conditions (such as cleanliness and low noise levels), each of which applies to a limited time period and provides little or no incremental harm or benefit once the desired threshold has been attained. It should be noted that the function in Figure 1c can also result when processes that increase and decrease strain occur jointly; simultaneous conservation and interference, carryover and depletion, and 


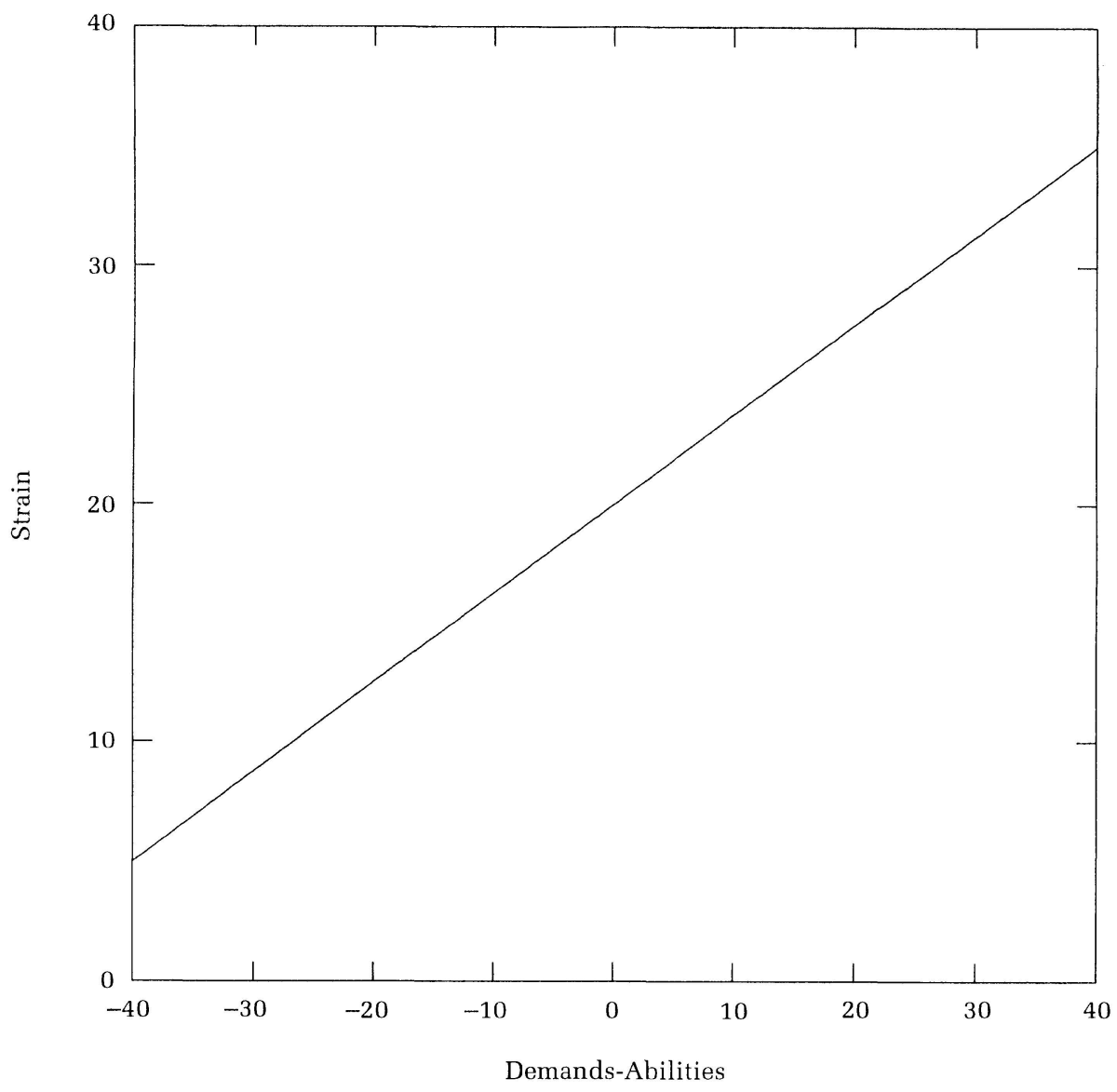

carryover on one dimension coupled with interference on another are examples.

\section{Demands-Abilities (D-A) Fit}

D-A fit refers to the match between environmental demands and a person's abilities. Abilities include the skills, knowledge, time, and energy the person can draw upon to meet environmental demands. Some abilities, such as skills and knowledge, can grow with use, whereas others, particularly mental and physical energy, decrease with use and must be replenished. Demands refer to quantitative and qualitative requirements placed on the person and can be objective (e.g., assembly line speed, length of work day) or socially constructed (e.g., group norms, role expectations). In either case, only demands that the person perceives can elicit stress (French et al., 1982; McGrath, 1976). Thus, the core mechanism underlying D-A fit is the cognitive 


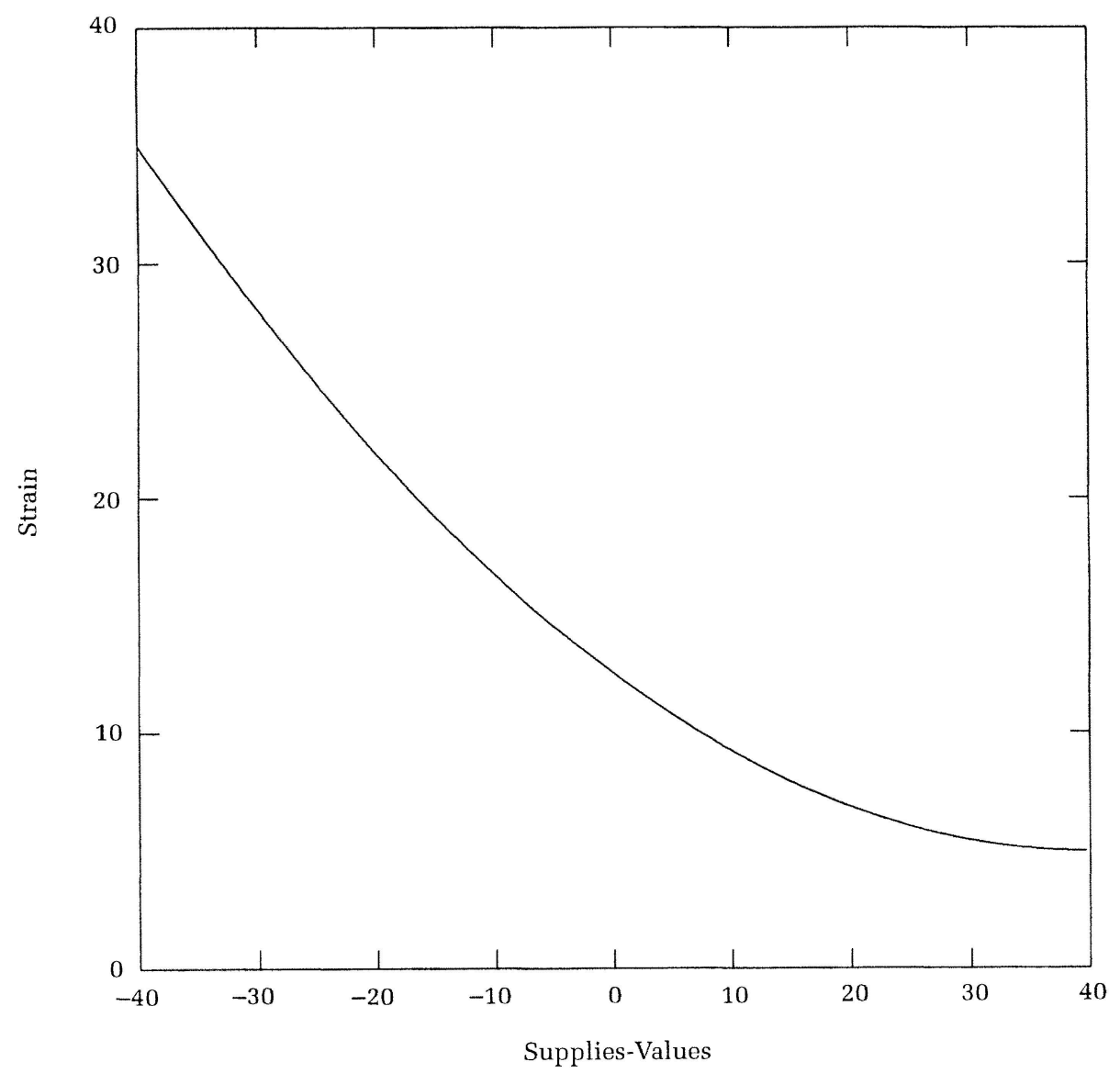

comparison of perceived environmental demands to the person's abilities to meet those demands.

Although most theories based on D-A fit predict that excess demands increase strain (for an exception, see McGrath [1976]), they differ regarding the effects of insufficient demands (or, equivalently, excess abilities). One approach to resolving these differences is to apply the concepts of carryover, conservation, interference, and depletion described earlier. Specifically, excess abilities may further reduce strain if they can be conserved to meet future demands, as when rest periods enable the person to handle upcoming tasks, or when excess time permits the person to work or plan ahead to make future demands more manageable. Carryover occurs when excess abilities pertaining to one demand are used to meet other demands. This may apply to time, energy, and general skills and aptitudes, which can often be directed toward pending demands once a focal demand is met. Carryover and conser- 


\section{Two-Dimensional Version of Asymptotic Model for D-A Fit}

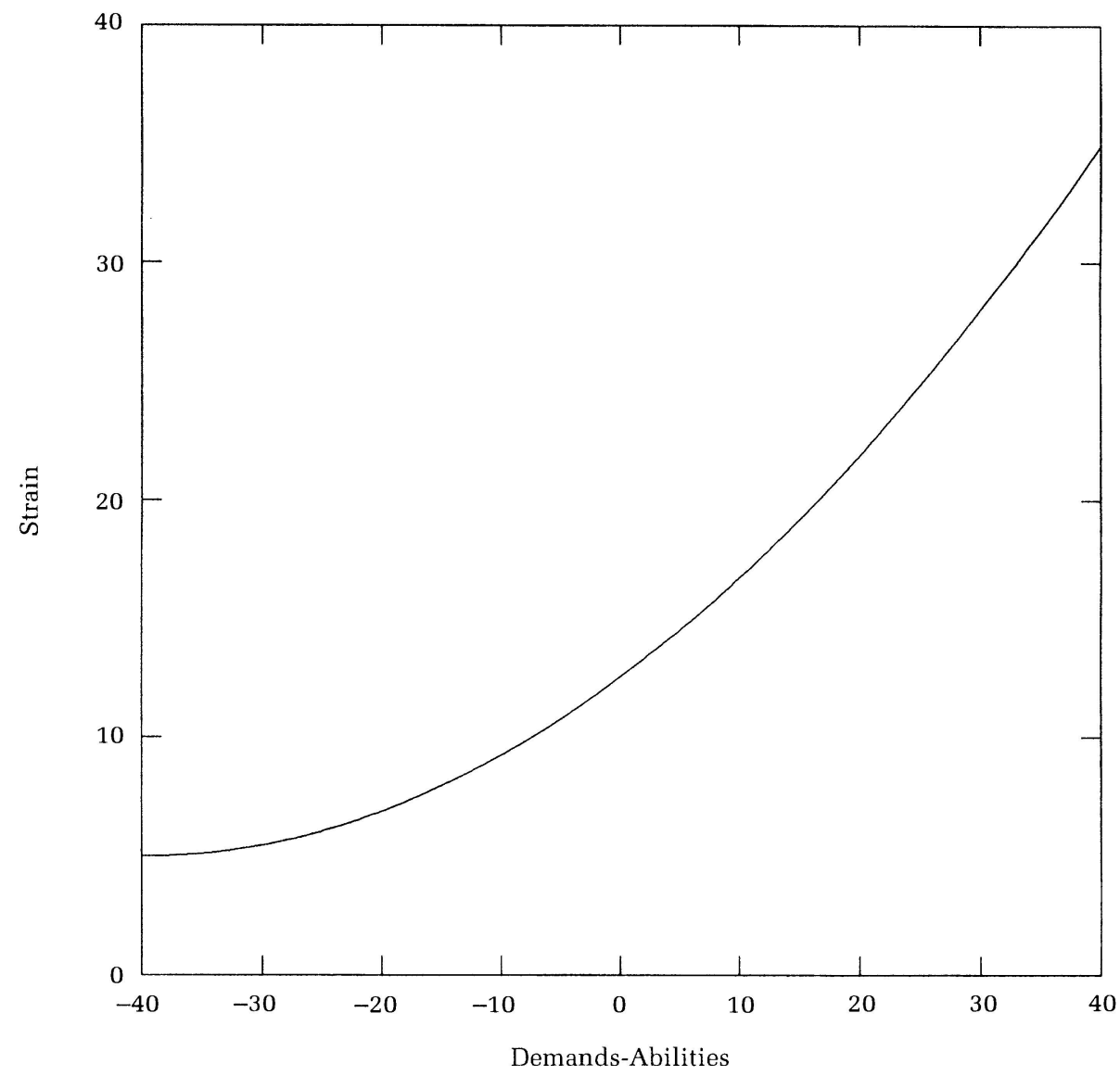

vation would yield a monotonic relationship between D-A fit and strain, as shown in Figure 1b.

In some cases, excess abilities may increase the likelihood that demands will exceed abilities at a later time, signifying a depletion effect. For instance, insufficient demands may cause unused skills to atrophy, so that future demands cannot be easily met (McGrath, 1970). Alternately, poor work scheduling may cause employees to alternate between underload and overload, so that slack time creates later periods of extreme exertion. Excess abilities may also produce interference, as when developing and maintaining specialized skills beyond those needed to meet job demands prevents a person from learning other required skills. Both depletion and interference would increase strain, indicating that a match between demands and abilities is optimal (Figure 1f).

Finally, excess abilities will not affect strain when they do not influence future abilities or demands on the same dimension and cannot be applied 


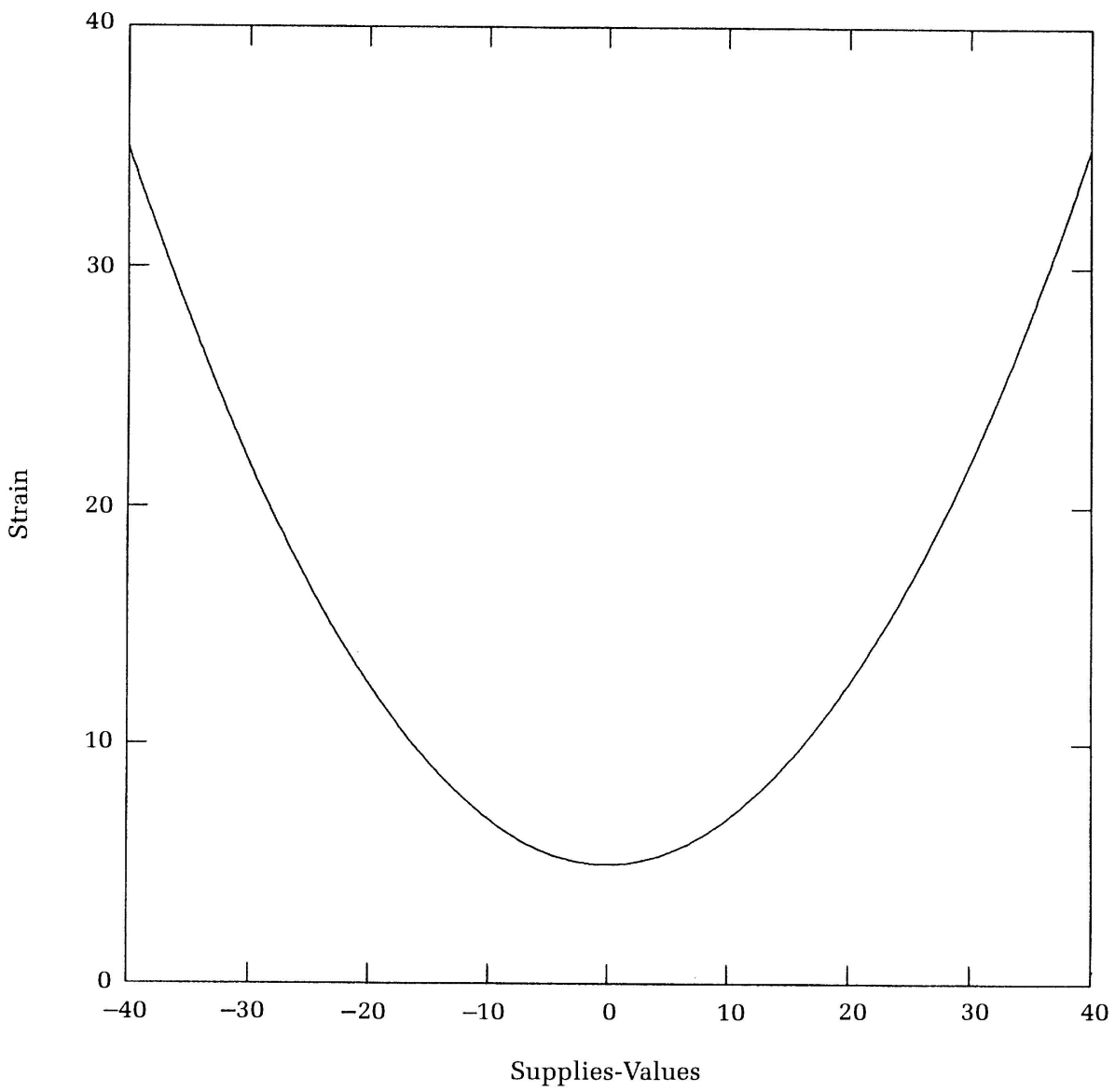

to other demands. For example, excess spatial ability, motor coordination, or manual dexterity are probably irrelevant to demands not specific to those abilities, and these abilities are largely innate and therefore are unlikely to deteriorate if left idle. In such cases, the overall relationship of D-A fit with strain would be asymptotic, as shown in Figure 1d. Note that this relationship may also occur when excess abilities invoke processes that increase and decrease strain simultaneously (i.e., conservation and interference, carryover and depletion, carryover and interference on separate dimensions).

\section{Relationships Between S-V Fit and D-A Fit}

The preceding discussion dealt with crossover and interference separately for S-V and D-A fit. However, these processes can also apply to relationships between S-V and D-A fit. For example, excess supplies regarding promotion rate can place people in positions in which job demands exceed their abilities, which would increase strain. On the other hand, excess supplies 


\section{Two-Dimensional Version of Optimal Model for D-A Fit}

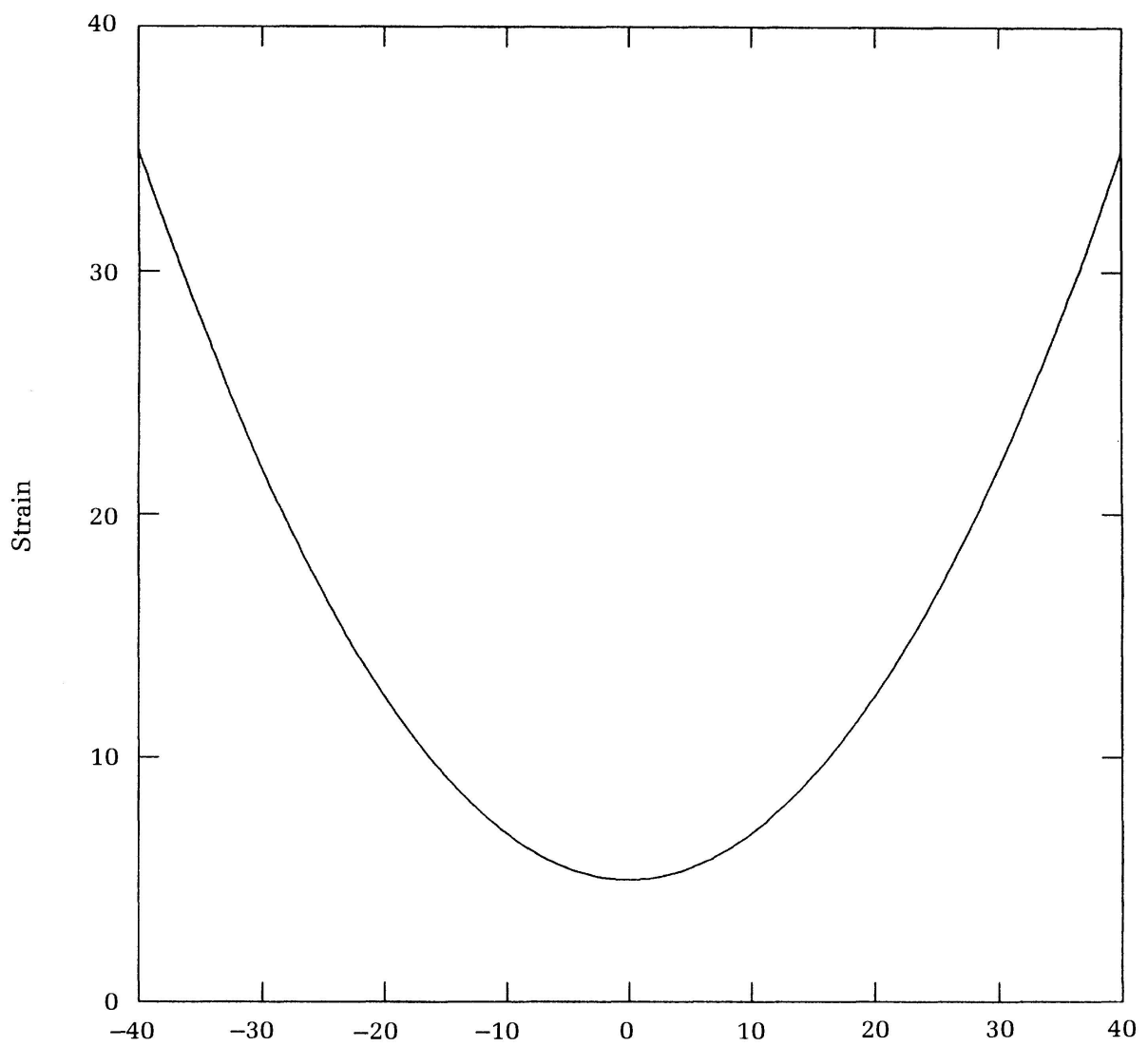

Demands-Abilities

for span of control may permit an individual to delegate work, thus reducing demands relative to abilities across multiple task dimensions. Excess abilities may create slack time that an employee can spend on leisure pursuits or with family, thereby fulfilling nonwork values and reducing strain. In contrast, excess abilities may interfere with the person's desire for stimulation and self-development, thus increasing strain. Hence, the effects of excess supplies and abilities depend upon conservation and depletion on the focal dimension as well as carryover and interference on other dimensions of both S-V and D-A fit.

\section{Moderators of the Relationship of S-V Fit and D-A Fit with Strain}

Several variables have been identified as potential moderators of the effects of S-V and D-A fit on strain (Caplan, 1987). One variable common to both $\mathrm{S}-\mathrm{V}$ and $\mathrm{D}-\mathrm{A}$ fit is importance, or the degree to which the dimension 
along which fit is cognitively evaluated is considered central to one's overall job or life (Edwards, 1992; Locke, 1976; Rice et al., 1985). Importance is hypothesized to intensify the effects of S-V and D-A fit on strain in such a way that misfit on more important dimensions yields greater strain than misfit on less important dimensions (Edwards, 1992; Harrison, 1985; McGrath, 1976; Sells, 1970).

Although importance may moderate the relationship of both S-V and D-A fit with strain, the psychological process underlying this effect differs for S-V and D-A fit. For S-V fit, the moderating effect of importance reflects the premise that misfit is more damaging for more strongly held values (Edwards, 1992; Locke, 1976; Rice et al., 1985; Schuler, 1980). For D-A fit, importance moderation is based on the degree to which misfit is linked to important consequences, meaning those that entail substantial rewards or costs for the person (McGrath, 1976; Sells, 1970). The evaluation of consequences in terms of their rewards and costs implies that the person determines whether these consequences are desirable or undesirable, much like the appraisal process underlying S-V fit. Thus, D-A misfit may be viewed as more important when it produces S-V misfit on other dimensions. This corresponds to an interference effect between $\mathrm{D}-\mathrm{A}$ and $\mathrm{S}-\mathrm{V}$ fit but suggests that D-A misfit may hinder S-V fit not only when abilities exceed demands, but also when demands exceed abilities.

\section{The Relative Merits of S-V Fit and D-A Fit}

As previously noted, there is some controversy regarding the comparative strengths of the S-V and D-A versions of fit. Shirom (1982) argued in favor of D-A fit, contending that S-V misfit represents job dissatisfaction and, hence, should be viewed as an outcome of stress rather than stress itself. In contrast, Harrison (1978) asserted that D-A misfit will produce strain only if failure to meet demands creates S-V misfit on other dimensions, or if meeting the demand itself is internalized as a value. Consequently, S-V misfit is directly related to strain, whereas D-A misfit yields strain only through its impact on S-V misfit. In this logic, stress is represented by $\mathrm{S}-\mathrm{V}$ misfit, whereas D-A misfit is considered one of its precursors.

There are two compelling reasons for viewing stress in terms of S-V misfit rather than D-A misfit. First, according to Locke (1976), dissatisfaction refers not to $\mathrm{S}-\mathrm{V}$ misfit itself, but rather to a negative emotional state resulting from S-V misfit. Hence, S-V fit does not confound stress with dissatisfaction, but instead casts them as distinct, causally related phenomena. Second, as noted earlier, proponents of D-A fit have argued that failure to meet demands will produce strain only if doing so yields substantial costs for the person (McGrath, 1976; Sells, 1970). These costs can be interpreted as signifying S-V misfit, in that they imply something of value that was lost or not obtained. This formulation suggests a causal sequence in which D-A misfit creates S$\mathrm{V}$ misfit, which in turn affects strain. If this sequence is correct, then $\mathrm{S}-\mathrm{V}$ misfit represents a necessary and sufficient condition for stress, whereas $D$ A misfit is considered stressful only if it induces S-V misfit. Moreover, the 
relationship between $\mathrm{S}-\mathrm{V}$ misfit and strain should be stronger than that for D-A misfit, given that the effects of D-A misfit are presumed to be fully mediated by S-V misfit. Accordingly, for both conceptual and empirical reasons, S-V fit should be preferred over D-A fit.

\section{EMPIRICAL EVIDENCE FOR S-V FIT AND D-A FIT}

The foregoing discussion has outlined the conceptual bases underlying $\mathrm{S}-\mathrm{V}$ and D-A fit, the processes linking both versions of fit to one another and to strain, the role of importance in moderating these effects, and the arguments for viewing stress as $\mathrm{S}-\mathrm{V}$ rather than $\mathrm{D}$-A misfit. This discussion relies almost exclusively on conceptual reasoning rather than empirical evidence, not because such evidence is absent (Edwards, 1991; Spokane, 1985), but because several serious shortcomings hinder studies of P-E fit. First, with few exceptions (e.g., French et al., 1982; Kalleberg, 1977), P-E fit studies have examined only a single functional form relating fit to strain (Edwards, 1991). The results of these studies are ambiguous, because a given relationship between fit and strain can yield significant effects for operationalizations $^{2}$ of fit representing a variety of distinct functional forms. For example, French and colleagues (1982) found that the relationship between S-V fit on job complexity and boredom was significant for difference scores representing the monotonic, asymptotic, and optimal models shown in Figures 1a, 1c, and 1e. This finding suggests that studies examining only one functional form may infer support for the form tested when the data actually provide stronger support for other functional forms (Edwards, 1991).

Second, of the few studies that have tested both S-V and D-A fit, none has examined them within the same taxonomic domain (Caplan, 1987). Consequently, these studies confound comparisons of S-V and D-A fit with differences in the dimensions along which fit is assessed. For example, French and colleagues (1982) examined S-V fit on six dimensions (e.g., job complexity, responsibility for persons) and D-A fit on two dimensions (e.g., length of service), but the content of these dimensions did not overlap. Although relationships with strain were generally stronger for S-V fit than for D-A fit, it is unclear whether these differences were due to the versions of fit tested or the dimensions along which fit was assessed.

Third, previous studies have relied almost exclusively on difference scores to operationalize fit. Use of these scores introduces numerous methodological problems, such as reduced reliability, confounded effects of environment and person, and the imposition of an untested set of constraints on the coefficients relating environment and person to strain (Cronbach \& Furby, 1970; Edwards, 1994; Johns, 1981; Wall \& Payne, 1973). More fundamentally, using difference scores reduces an inherently three-dimensional relationship

${ }^{2}$ Generally, "operationalization” refers to the translation of a theoretical construct into an empirical measure. In this context, the term describes the mathematical combination of person and environment measures into a single score. 
between environment, person, and strain to two dimensions (Edwards, 1994). Figure $2(2 \mathrm{a}-2 \mathrm{f})$, which depicts three-dimensional versions of the monotonic, asymptoic, and optimal models for S-V and D-A fit shown in Figure 1 , shows this reduction. Given that environment, person, and strain represent conceptually distinct constructs, their analysis requires a threedimensional approach.

In earlier research (Edwards, 1994), I developed a procedure that avoids the preceding problems. This procedure involves regressing strain on environment, person, and selected higher-order terms, such as the squares of environment and person and their product. By retaining environment and person as separate predictors, problems of reduced reliability are minimized, the effects of environment and person are no longer confounded, and the three-dimensional relationship between environment, person, and strain is

FIGURE 2a

\section{Three-Dimensional Version of Monotonic Model for S-V Fit}

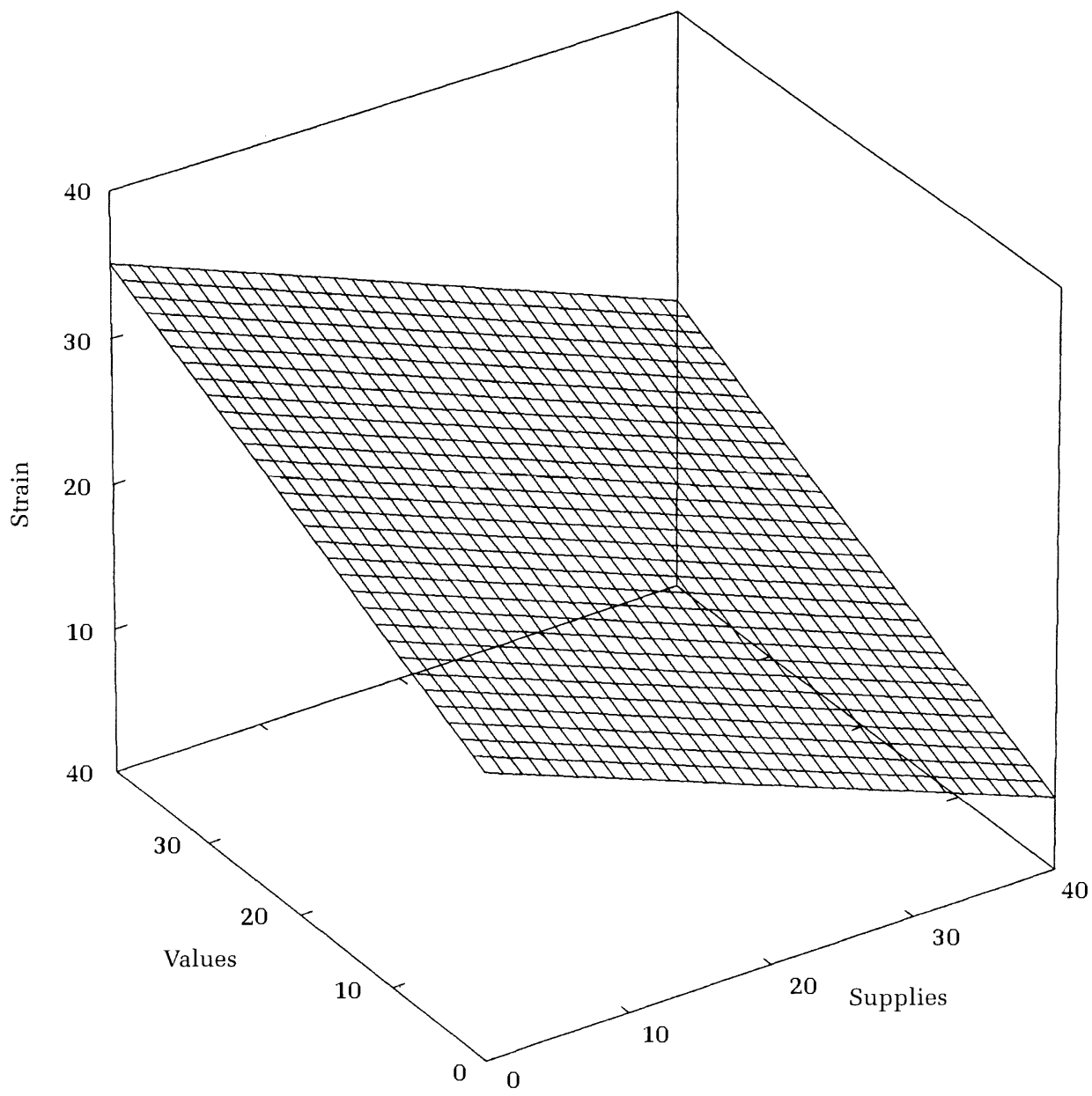




\section{FIGURE 2b}

\section{Three-Dimensional Version of Monotonic Model for D-A Fit}

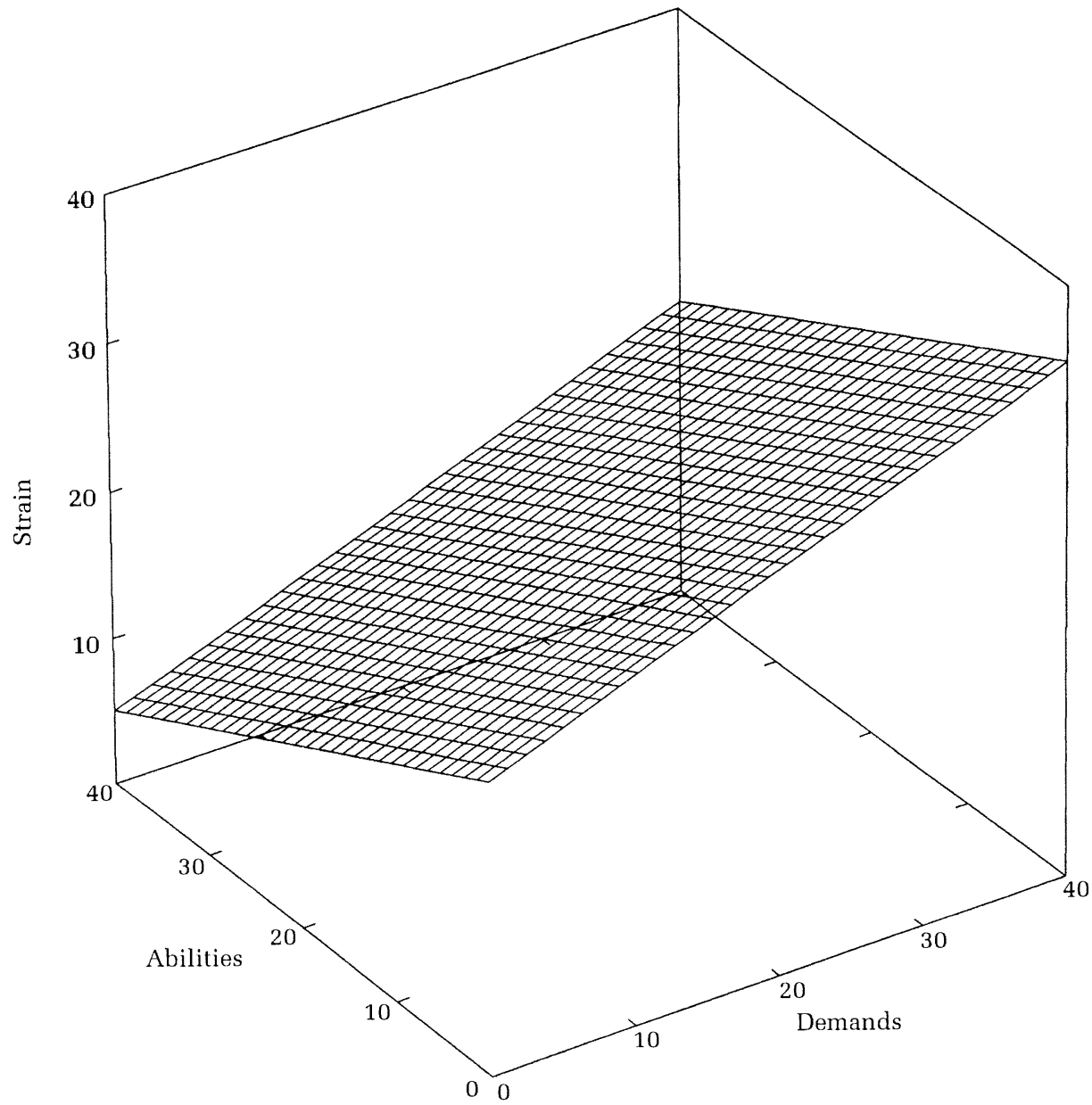

preserved. Furthermore, by testing the direction and relative magnitude of coefficients on environment, person, and higher-order terms, constraints imposed by difference scores can be tested. Studies using this procedure (Edwards, 1994; Edwards \& Harrison, 1993; cf. Hesketh \& Gardner, 1993; Irving \& Meyer, 1994; Warr, 1990) have more than doubled the variance explained in strain and show that difference scores often oversimplify the three-dimensional relationship between environment, person, and strain.

\section{THE PRESENT STUDY}

This study empirically examined the S-V and D-A versions of the P-E fit approach to stress. Problems with previous P-E fit research were avoided by testing multiple functional forms relating fit to strain, measuring $\mathrm{S}-\mathrm{V}$ and D-A fit within the same taxonomic domain, and applying a procedure 


\section{FIGURE 2C}

\section{Three-Dimensional Version of Asymptotic Model for S-V Fit}

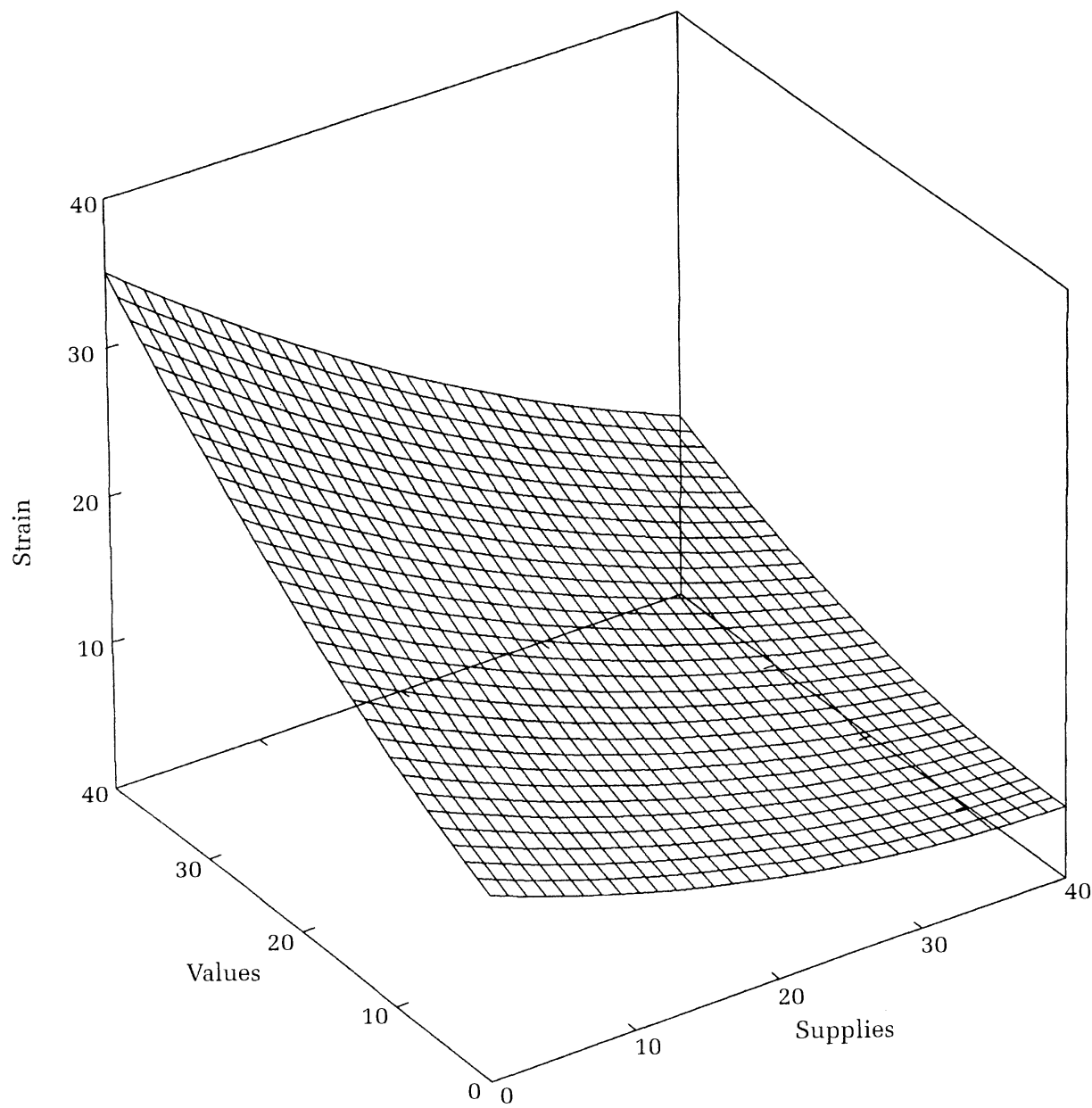

developed to avoid problems with difference scores (Edwards, 1994; Edwards \& Parry, 1993). Hypotheses regarding the relationships of S-V and DA fit with strain were derived from the conceptual principles discussed earlier. As this discussion indicated, the relationship between fit and strain depends on the dimension along which fit is assessed. The dimensions examined in this study were managerial task activities, which were chosen because they could be meaningfully measured in terms of all relevant environment and person constructs.

The preceding discussion of S-V fit suggests that insufficient task supplies will be associated with increased strain. Excess task supplies probably cannot be conserved, given that tasks do not represent resources that can be saved for later use. However, excess task supplies may produce carryover to other dimensions of S-V fit, in that larger amounts of managerial tasks signify 
FIGURE 2d

Three-Dimensional Version of Asymptotic Model for D-A Fit

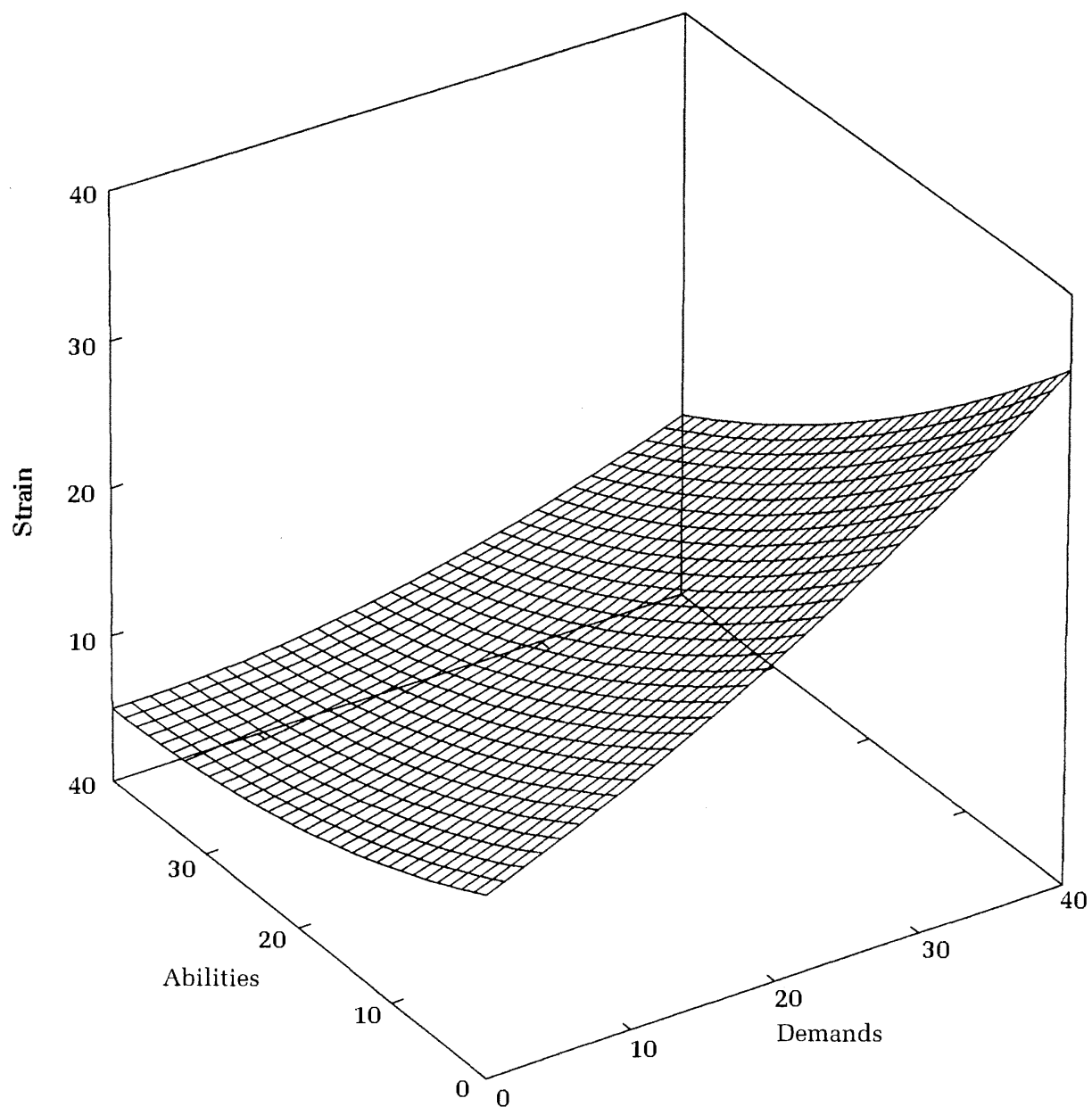

greater responsibility, which may bring about valued organizational rewards (Harrison, 1978). Excess tasks may, however, produce depletion, in that performing large amounts of a task at one time may make it unnecessary to perform that task at a later time. Moreover, excess tasks will likely create $\mathrm{S}-\mathrm{V}$ interference, in that extra time spent on one task prevents allocating time to other tasks. Likewise, excess tasks may interfere with D-A fit by generating cumulative demands that exceed a person's abilities. Combining carryover with depletion and interference suggests that, overall, excess task supplies will increase strain, although the strength of this effect may be somewhat less than that associated with insufficient supplies. Hence,

Hypothesis 1: Strain will increase as supplies exceed or fall short of values. 


\section{FIGURE 2e}

Three-Dimensional Version of Optimal Model for S-V Fit

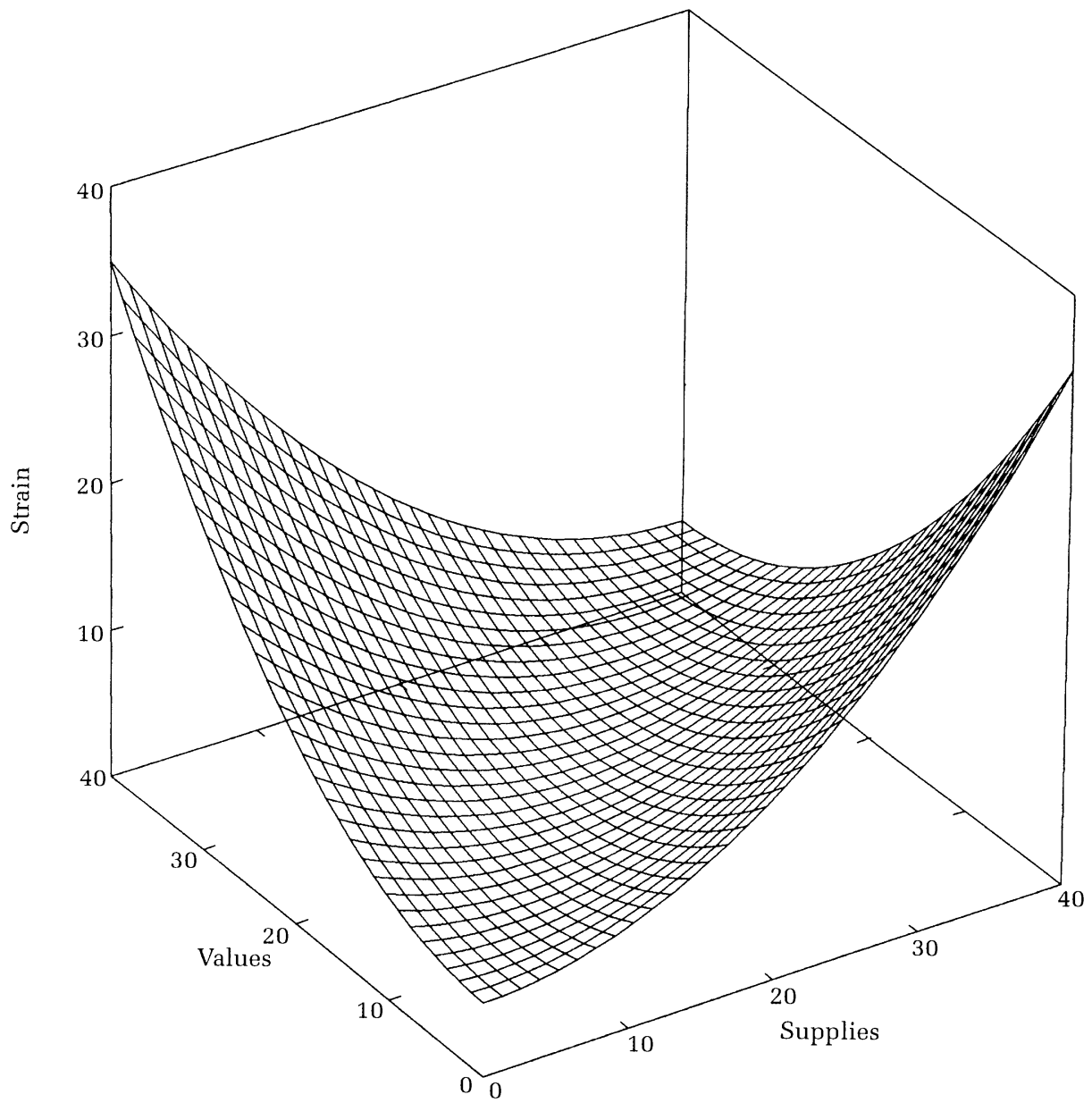

Drawing from the previous discussion of D-A fit, it is likely that excess task demands will be associated with increased strain. Excess task abilities (or insufficient task demands) probably cannot be conserved, because they represent qualitative as opposed to quantitative resources such as time and energy. However, excess task abilities may carry over to other demands, presuming they represent a proxy for general managerial aptitudes. Excess task abilities may also imply skills at delegating work, which may reduce the total demands a manager must personally fulfill. Moreover, excess abilities may carry over to S-V fit by fulfilling values of competence and expertise (White, 1959). On the other hand, excess abilities may be subject to depletion, assuming that task abilities can atrophy if not used. Excess task abilities seem unlikely to create interference on other dimensions of D-A fit, but they may interfere with S-V fit on dimensions such as stimulation and self- 


\section{FIGURE 2f}

Three-Dimensional Version of Optimal Model for D-A Fit

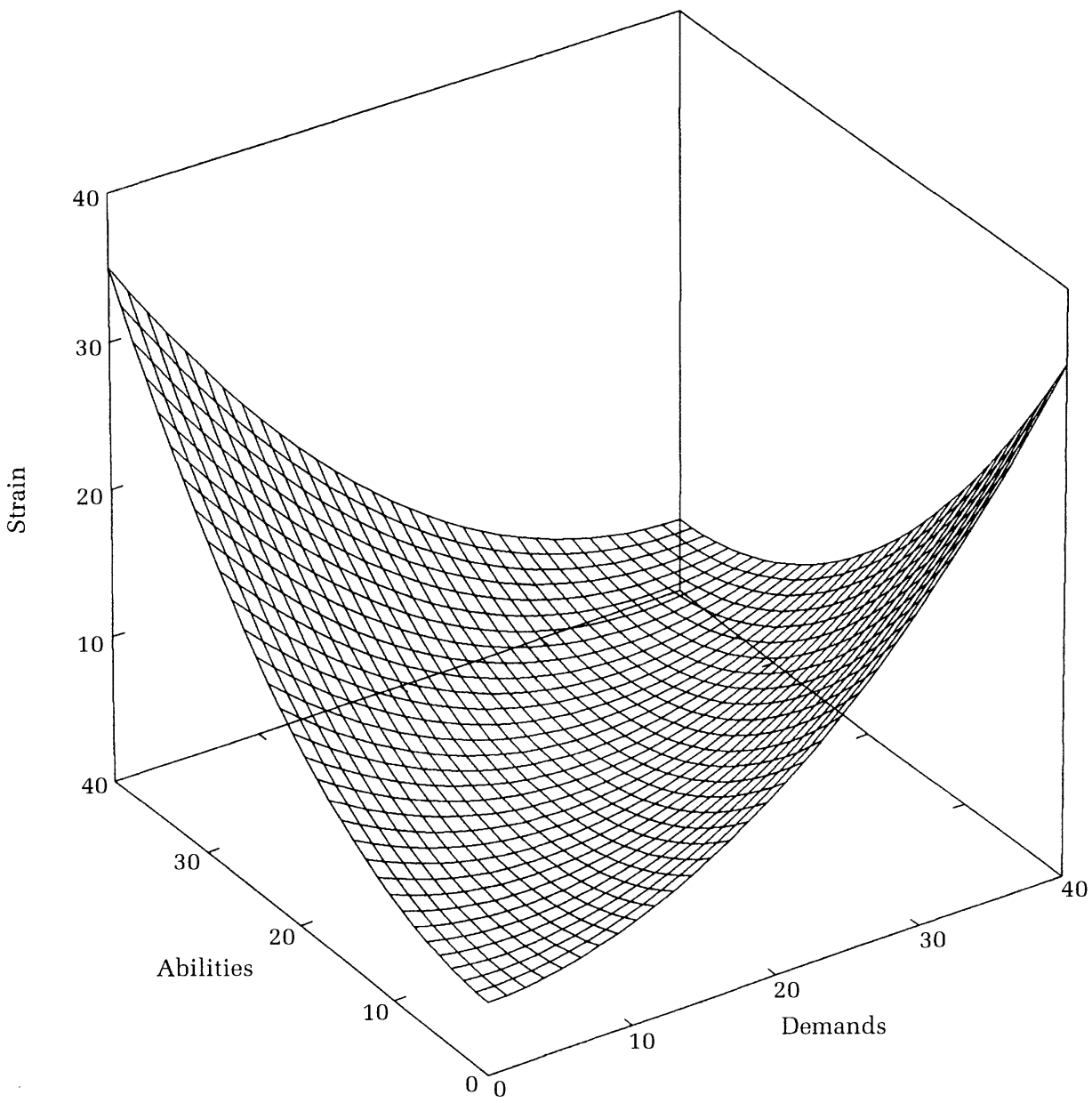

actualization. Overall, the carryover effects of excess task abilities to both S-V and D-A fit may offset the depletion and interference effects combined, yielding an asymptotic relationship with strain.

Hypothesis 2: Strain will increase as demands exceed abilities but will remain constant as abilities exceed demands.

Importance will moderate the relationship of S-V and D-A fit on task activities with strain in such a way that misfit on tasks considered more important will yield greater strain than misfit on tasks considered less important. This effect is expected for all functional forms relating fit to strain (Locke, 1976). Thus,

Hypothesis 3: As importance increases, the relationship of $S-V$ misfit with strain will become stronger (i.e., the 
slope of the relationship between $S$ - $V$ misfit and strain will become steeper).

Hypothesis 4: As importance increases, the relationship of $D$-A misfit with strain will become stronger (i.e., the slope of the relationship between $D-A$ misfit and strain will become steeper).

Finally, the conceptual arguments outlined earlier imply that S-V misfit on task activities is a necessary and sufficient condition for stress, whereas D-A misfit will be experienced as stressful only if it invokes S-V misfit. $\mathrm{S}-\mathrm{V}$ misfit should therefore exhibit a stronger relationship with strain. Hence,

Hypothesis 5: The relationship between P-E misfit and strain will be stronger for $S-V$ misfit than for $D-A$ misfit.

\section{METHODS}

\section{Sample and Measures}

Data were collected from 494 entering students at a major graduate business school in the eastern United States. Analyses used data from 428 respondents employed during the preceding year in positions requiring responsibility for subordinates. This condition was required because all questions presumed recent work experience, and many referenced supervisory tasks, such as evaluating performance. Positions held by respondents were in finance $(18 \%)$, consulting $(16 \%)$, investments $(13 \%)$, marketing $(11 \%)$, and operations $(10 \%)$, with the remainder in human resource management, sales, corporate planning, and other functions, Members of the final sample averaged 27 years of age and five years' work experience, and most were Caucasian $(88 \%)$ and male $(72 \%)$. The initial and final samples did not differ on these dimensions.

Respondents completed four-item measures of supplies, values, demands, abilities, importance, and two forms of strain-job dissatisfaction and tension-in reference to five sets of managerial tasks. Job dissatisfaction and tension were chosen as indexes of strain for two reasons. First, their extensive examination in stress research (Beehr \& Newman, 1978; Cooper \& Marshall, 1976; French \& Caplan, 1972; Ganster \& Schaubroeck, 1991; Jackson \& Schuler, 1985; Kahn \& Byosiere, 1990) establishes a link between this literature and the present study. Second, job dissatisfaction and tension items can be phrased in terms of specific task activities, which was required to create fully commensurate measures of environment, person, and strain. In contrast, global measures of strain, such as anxiety, depression, and physical symptoms, refer to a person's overall well-being and therefore cannot be readily phrased in terms of a specific task.

The instrument used in the study consisted of a matrix, with tasks listed along the rows and supplies, values, demands, abilities, importance, job dissatisfaction, and tension listed across the columns (cf. Little, 1983). Respondents rated each task item in terms of each environment, person, and 
strain construct by inserting a number ranging from 0 to 10 into the appropriate cell of the matrix, sequentially working down each column. All tasks were rated in reference to the respondent's most recent job, which the respondent had left approximately four to six weeks prior to the time of measurement. Scales were formed by summing the four items corresponding to each task for each construct.

Tasks used in the instrument were adapted from the Leader Observation System (LOS; Luthans \& Lockwood, 1984), a 67-item measure of 12 managerial task areas. To identify a parsimonious but representative set of tasks, I factor-analyzed LOS subscale correlations reported by Luthans and Lockwood. Given the results of a scree test (Cattell, 1966) and factor interpretability, a five-factor solution was chosen, representing planning-coordinating, processing paperwork, exchanging information, decision making, and motivating-rewarding others. Four items were selected from representative subscales to measure each task dimension.

Supplies and values were measured by asking respondents how much of each task was involved in their job and how much of each task they would have liked in their job. I measured demands and abilities by first asking the level of skill required for each task and then by asking the respondent to assess his or her own skill regarding that task. Importance was measured by asking respondents how important they felt each task was to their job as a whole. Job dissatisfaction was measured by asking respondents how satisfied they were with a task as it existed in their jobs (ranging from "very dissatisfied" to "very satisfied"; reverse-scored), and tension was measured by asking respondents how much tension they experienced when performing the task.

\section{Analysis}

For S-V and D-A fit, the monotonic, asymptotic, and optimal models were tested with multiple regression analysis, using either job dissatisfaction or tension as the dependent variable and the appropriate environment and person measures as independent variables, supplemented by the higherorder terms necessary to test each model. All three models were tested to determine whether the support for the hypothesized model was stronger than that for the other two competing models. I compared S-V and D-A fit via their $R^{2}$ values and by testing the increment in variance explained by terms from one version of fit after controlling for terms from the other. Prior to analysis, I scale-centered environment and person measures by subtracting 20 (i.e., the midpoint of each scale), thereby reducing multicollinearity and allowing meaningful interpretation of coefficients on first-order terms (i.e., the slope at the scale midpoint) (Aiken \& West, 1991; Edwards, 1994; Jaccard, Turrisi, \& Wan, 1990).

Testing models of fit. Tests of the monotonic, asymptotic, and optimal models began by writing a regression equation representing the functional form corresponding to each model and identifying the constraints imposed by the equation (Edwards, 1994). For example, the monotonic model for $\mathrm{S}-\mathrm{V}$ fit indicates that strain decreases as supplies approach values and contin- 
ues to decrease as supplies exceed values (Figure 1a). An equation corresponding to this model uses the algebraic difference between supplies and values (i.e., $S-V$ ) to predict strain (here labeled $Z$ ):

$$
Z=\mathrm{b}_{0}-\mathrm{b}_{1}(S-V)+\mathrm{e} .
$$

Expanding this equation yields:

$$
Z=\mathrm{b}_{0}-\mathrm{b}_{1} S+\mathrm{b}_{1} V+\mathrm{e} .
$$

Equation 2 shows that the monotonic model implies a negative coefficient on $S$ and a positive coefficient of equal magnitude on $V$ (see Figure 2a). The constraints imposed by this equation are identified by writing an equation that simply contains $S$ and $V$ as separate predictors:

$$
Z=\mathrm{b}_{0}+\mathrm{b}_{1} S+\mathrm{b}_{2} V+\mathrm{e} .
$$

Comparing Equation 3 to Equation 2 shows that the monotonic model constrains the coefficients on $S$ and $V$ to be equal in magnitude but opposite in sign (Edwards \& Cooper, 1990). The same constraint applies to D-A fit, except that the coefficient on $D$ is positive and the coefficient on $A$ is negative (Figure 2b).

The optimal model posits that, for both S-V and D-A fit, strain increases symmetrically on either side of the point of perfect fit (Figures $1 \mathrm{e}$ and $1 \mathrm{f}$ ). The corresponding equation uses a squared difference to predict strain. For $\mathrm{S}-\mathrm{V}$ fit, this equation is as follows:

$$
Z=\mathrm{b}_{0}+\mathrm{b}_{1}(S-V)^{2}+\mathrm{e} .
$$

Expanding and rearranging terms yields:

$$
Z=\mathrm{b}_{0}+\mathrm{b}_{1} S^{2}-2 \mathrm{~b}_{1} S V+\mathrm{b}_{1} V^{2}+\mathrm{e} .
$$

Now consider a quadratic equation containing $S, V, S^{2}, S V$, and $V^{2}$ as separate predictors ( $S$ and $V$ are included because they are components of the curvilinear and interactive terms $S^{2}, S V$, and $V^{2}$; see Cohen \& Cohen [1983]):.

$$
Z=\mathrm{b}_{0}+\mathrm{b}_{1} S+\mathrm{b}_{2} V+\mathrm{b}_{3} S^{2}+\mathrm{b}_{4} S V+\mathrm{b}_{5} V^{2}+\mathrm{e} .
$$

Comparing Equations 5 and 6 shows that the squared difference imposes four constraints: (1) the coefficient on $S$ is zero, (2) the coefficient on $V$ is zero, (3) the coefficients on $S^{2}$ and $V^{2}$ are equal, and (4) the coefficients on $S^{2}, S V$, and $V^{2}$ sum to zero. ${ }^{3}$ The same constraints apply to D-A fit, with $D$ and $A$ replacing $S$ and $V$, respectively.

The asymptotic model for $\mathrm{S}-\mathrm{V}$ fit indicates that strain drops as $S$ increases toward $V$ but remains essentially constant as $S$ exceeds $V$, as depicted by the left half of a U-shared parabola (Figure 1c). This model can be represented by rescaling the quantity $(S-V)$ by subtracting its theoretical maximum

${ }^{3}$ Given the third constraint, the fourth constraint is equivalent to stating that the coefficient on $S V$ is twice as large as the coefficient on either $S^{2}$ or $V^{2}$, but opposite in sign (Edwards, 1994). 
(here labeled $m$ ), such that $(S-V)$ can take on only negative values, and then using the square of the resulting score as a predictor of strain:

$$
Z=\mathrm{b}_{0}+\mathrm{b}_{1}([S-V]-\mathrm{m})^{2}+\mathrm{e} .
$$

Expanding and rearranging terms yields:

$$
Z=\mathrm{b}_{0}+\mathrm{b}_{1} \mathrm{~m}^{2}-2 \mathrm{mb}_{1} S+2 \mathrm{mb}_{1} V+\mathrm{b}_{1} S^{2}-2 \mathrm{~b}_{1} S V+\mathrm{b}_{1} V^{2}+\mathrm{e} .
$$

Comparing Equation 8 to its unconstrained version (Equation 6) reveals four constraints: (1) the coefficients on $S$ and $V$ are equal in magnitude but opposite in sign, (2) the coefficients on $S^{2}$ and $V^{2}$ are equal, (3) the coefficients on $S^{2}, S V$, and $V^{2}$ sum to zero, and (4) the coefficient on $S$ is $2 \mathrm{~m}$ times the coefficient on $S^{2}$, but opposite in sign. ${ }^{4}$ It should be noted that the term $\mathrm{b}_{1} \mathrm{~m}^{2}$ in Equation 8 simply shifts the intercept and need not be considered when testing the model. Constraints for the asymptotic model for D-A fit are derived in a similar manner, except that the quantity D-A is rescaled by adding $\mathrm{m}$, such that $(D-A)$ can take on only positive values. The resulting constraints are identical to those for S-V fit with $D$ and $A$ replacing $S$ and $V$, except that the coefficient on $D$ is positive and the coefficient on $A$ is negative.

After identifying the appropriate constraints, I tested each model as follows. First, the $R^{2}$ for the unconstrained equation was tested. Next, individual coefficients were tested to determine whether they were significant and in the expected direction. Third, the constraints were tested as a set by imposing them on the unconstrained equation and examining the reduction in $R^{2}$. Finally, terms one order higher than those in the equation were tested as a set to determine whether the model was sufficiently complex to depict the underlying surface. For the monotonic model, three quadratic terms were tested (i.e., $S^{2}, S V$, and $V^{2}$ for S-V fit; $D^{2}, D A$, and $A^{2}$ for D-A fit), and for the asymptotic and optimal models, four cubic terms were tested (i.e., $S^{3}, S^{2} V$, $S V^{2}$, and $V^{3}$ for S-V fit; $D^{3}, D^{2} A, D A^{2}$, and $A^{3}$ for D-A fit). Support for a model was inferred if: (1) the $R^{2}$ for the unconstrained equation was significant, (2) the appropriate coefficients were significant and in the expected directions, (3) the set of constraints implied by the model was not rejected, and (4) the set of terms one order higher than those indicated by the model was not significant (Edwards, 1994).

Evaluating statistical power. Support for the constraints imposed by the monotonic, asymptotic, and optimal models required that the difference in $R^{2}$ between the constrained and unconstrained equations for each model was not significant, which necessitated adequate statistical power to detect true differences (Cohen, 1988). With alpha at .05 and a sample size of 356 (the smallest used in any of the unconstrained equations), power was .80

${ }^{4}$ Given the first three constraints, the fourth is equivalent to stating that (1) the coefficient on $S$ is m times the coefficient on $S V$, (2) the coefficient on $S$ is $2 \mathrm{~m}$ times the coefficient on $V^{2}$, but opposite in sign, (3) the coefficient on $V$ is $2 \mathrm{~m}$ times the coefficient on $S^{2}$, (4) the coefficient on $V$ is m times the coefficient on $S V$, but opposite in sign, or (5) the coefficient on $V$ is $2 \mathrm{~m}$ times the coefficient on $V^{2}$. 
for detecting differences in $R^{2}$ of about .020 for the monotonic model and .030 for the asymptotic and optimal models. As will be seen, actual differences in $R^{2}$ were generally much larger, averaging .056 for the monotonic model, .087 for the asymptotic model, and .091 for the optimal model.

Testing the moderating effects of importance. The moderating effects of importance were tested using hierarchical regression analysis (Cohen \& Cohen, 1983). I created product terms by multiplying each term in the unconstrained equations by importance (here labeled $I$ ). I then tested the increment in $R^{2}$ yielded by these terms, controlling for importance and the original terms in the equation. If the increment in $R^{2}$ was significant, the coefficients were examined to determine whether importance intensified the relationship with strain, as Hypotheses 3 and 4 predict. Support was inferred if the coefficients on the terms multiplied by importance conformed to the constraints for the model in question; for instance, for the monotonic model for S-V fit, the coefficients on $I S$ and $I V$ should be negative and positive, respectively, and of equal magnitude.

Screening data for outliers and influential observations. Belsley, Kuh, and Welsch defined an influential observation as one that "has a demonstrably larger impact on the calculated values of various estimates (coefficients, standard errors, $t$-values, etc.) than is the case for most of the other observations" (1980: 11). Such observations could profoundly affect tests of the monotonic, asymptotic, and optimal models, which predicted specific patterns of regression coefficients. Therefore, I screened Equations 3 and 6 for outliers and influential observations, using leverage (i.e., diagonal values of the hat matrix), studentized residuals, DFITS, and Cook's $D$-statistic (Belsley et al., 1980; Fox, 1991) as criteria. Observations that exceeded the minimum cutoff on all four criteria (Bollen \& Jackman, 1990) and were clearly discrepant on plots combining information from the criteria were dropped from the equation in question (this affected no more than four observations per equation).

Controlling type I error. The analyses described above entailed numerous regression analyses, thereby risking inflated type I error rates. To control this possibility, I used the sequential Bonferroni procedure described by Holm (1979) and advocated by Seaman, Levin, and Serlin (1991). First, it was necessary to define the families of tests for which type I error would be controlled. For both versions of fit, a family comprised the tests of the $R^{2}$ from the unconstrained equation for a given model, collapsed across all task dimensions and both measures of strain (Hochberg \& Tamahane, 1987; Miller, 1981). Next, I listed the obtained probability levels for the tests within a family in ascending order. The first (i.e., smallest) probability was multiplied by the total number of tests (the standard Bonferroni correction), the second probability was multiplied by the total number of remaining tests, and so forth until all probabilities were corrected. For each $R^{2}$ that reached significance, I tested coefficients from the equation using the nominal alpha level (i.e., .05). This procedure struck a balance between type I and type II error by examining only those equations that reached significance at the required "familywise" 
alpha, but then testing the coefficients from those equations in the usual manner. Probabilities were also corrected for tests of the $R^{2}$ from unconstrained equations containing importance, with families defined in the same manner.

\section{RESULTS}

\section{Reliability and Intercorrelation of Measures}

Reliability estimates (Cronbach's alpha) were calculated for the environment, person, and strain measures for the five task dimensions (see Table 1). With two exceptions, reliabilities for the planning-coordinating, decision making, and motivating-rewarding measures exceeded the .70 criterion (Nunnally, 1978). In contrast, the processing paperwork and exchanging information measures yielded reliabilities ranging from .48 to .63 (median $=.54$ ) and, hence, were excluded from further analysis. For each of the three remaining task dimensions, confirmatory factor analyses of the seven environment, person, and strain measures indicated that all disattenuated factor correlations were significantly less than unity, thereby supporting the discriminant validity of the measures (Bagozzi \& Phillips, 1982). ${ }^{5}$

\section{Tests of the Monotonic, Asymptotic, and Optimal Models}

Table 2 shows unconstrained equations for the monotonic, asymptotic, and optimal models for S-V fit. For the monotonic model, coefficients on $S$ and $V$ were significant and in the predicted directions for planning-coordinating and motivating-rewarding predicting job dissatisfaction. However, the constraint for the monotonic model was rejected $\left(F_{1,392}=23.31\right.$ for planningcoordinating; $F_{1,387}=32.08$ for motivating-rewarding, both $p<.05$ ). Moreover, significant higher-order terms were found $\left(F_{3,389}=23.83\right.$ for planningcoordinating; $F_{3,384}=14.63$ for motivating-rewarding, both $p<.05$ ), indicating that the surfaces relating supplies and values to dissatisfaction deviated from the simple plane associated with the monotonic model (Figure 2a).

For the optimal model, the coefficients on $S^{2}, S V$, and $V^{2}$ followed the expected pattern for planning-coordinating predicting job dissatisfaction, but the coefficent on $S$ was also negative and significant, and the constraints for the model were rejected $\left(F_{4,389}=12.60, p<.05\right)$. For the asymptotic model, the equation for planning-coordinating predicting job dissatisfaction yielded the expected pattern of coefficients for $S, S^{2}, S V$, and $V^{2}$, but the coefficient on $V$ was not significant, and the constraints for the model were rejected $\left(F_{4,389}=18.87, p<.05\right)$. Thus, the relationship between S-V fit and strain did not support the optimal model (as predicted by Hypothesis 1 ) or the monotonic or asymptotic models (see Figure 2).

Table 3 reports results for the unconstrained equations for D-A fit. For the monotonic model, coefficients on $D$ and $A$ were significant and in the

${ }^{5}$ A summary of the results of the three confirmatory factor analyses can be obtained from the author. 


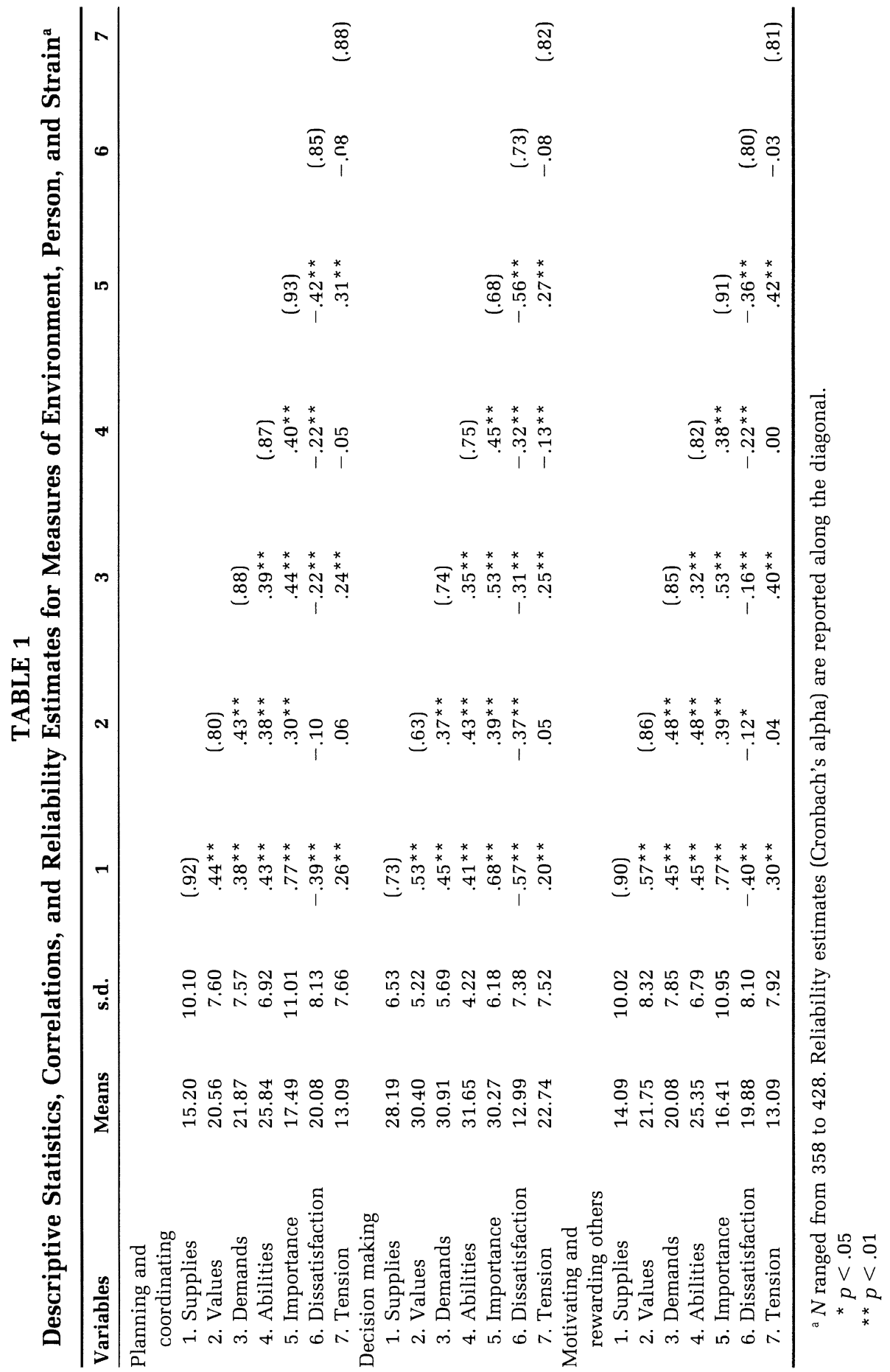




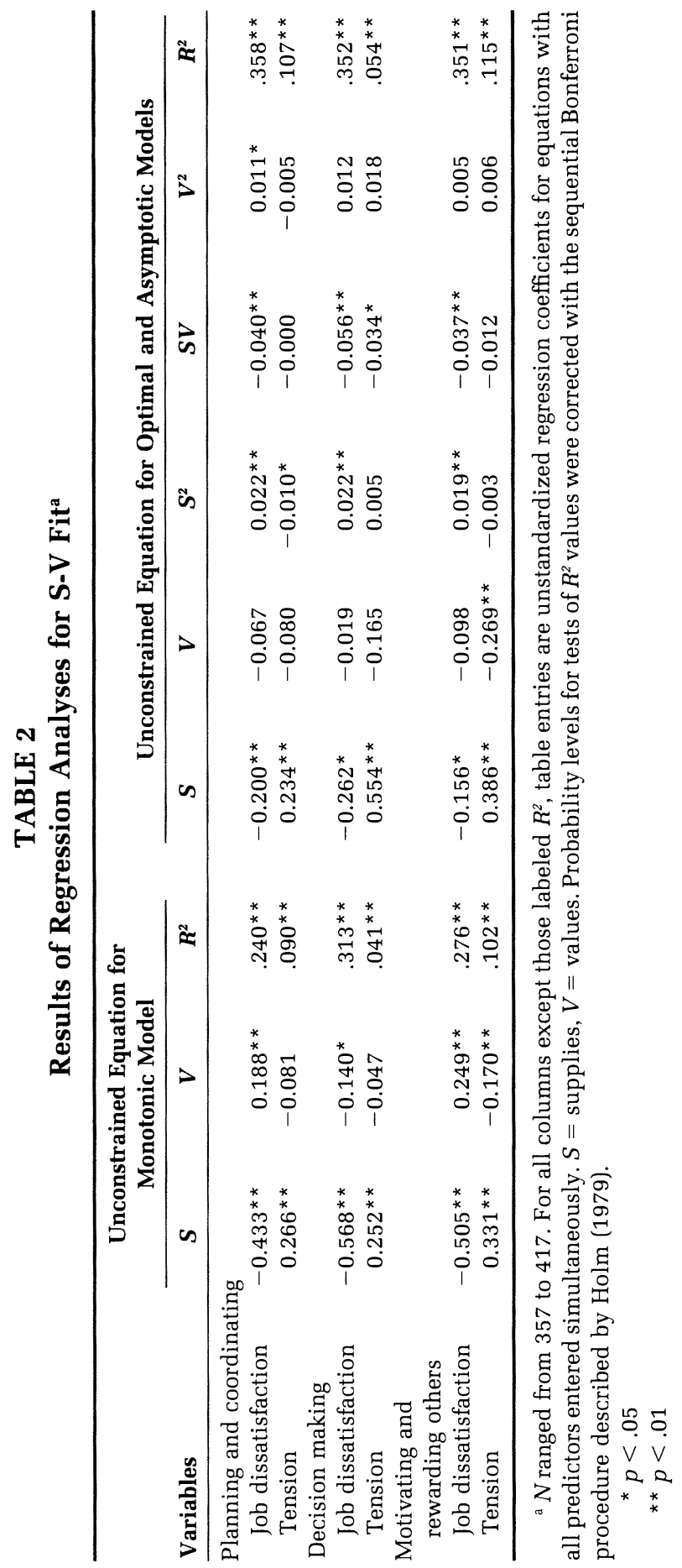




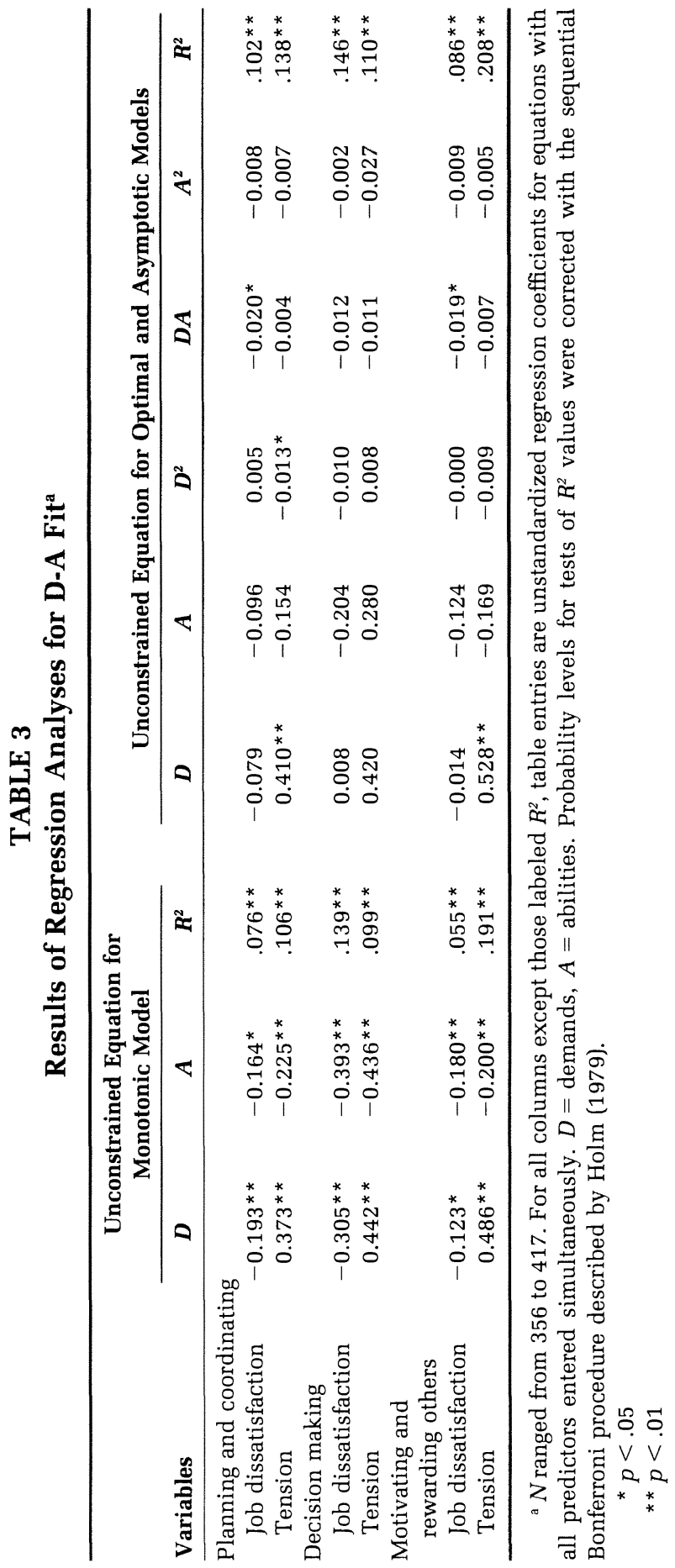


appropriate direction for all three task dimensions predicting tension. However, the constraint for the model was rejected for planning-coordinating and motivating-rewarding $\left(F_{1,355}=5.05\right.$ and $F_{1,353}=19.26$, respectively, both $p<.05$ ), and significant higher-order terms were found for planning-coordinating $\left(F_{3,352}=4.27, p<.05\right)$. In contrast, the constraint was not rejected for decision making $\left(F_{1,412}=0.01, p>.05\right)$, and higher-order terms were not significant $\left(F_{3,409}=1.79, p>.05\right)$. For the asymptotic and optimal models, none of the six equations yielded the expected pattern of coefficients. These results support the monotonic model for decision making predicting tension but fail to support the asymptotic model (contrary to Hypothesis 2) or the optimal model.

\section{Tests of the Moderating Effects of Importance}

For S-V fit, tests of the moderating effects of importance for the monotonic model indicated that terms representing the product of importance with $S$ and $V$ (i.e, $I S$ and $I V$ ) were jointly significant for all three task dimensions predicting job dissatisfaction $\left(F_{2,389}=25.74\right.$ for planning-coordinating; $F_{2,411}$ $=11.41$ for decision making; $F_{2,383}=21.29$ for motivating-rewarding; all $p<$ $.05)$. However, the coefficients on the $I S$ and $I V$ terms were positive and negative, respectively, contrary to the predictions for the monotonic model. For the optimal and asymptotic models predicting job dissatisfaction, the terms multiplied by importance (i.e., $I S, I V, I S^{2}, I S V, I V^{2}$ ) were jointly significant for decision making $\left(F_{5,405}=3.25, p<.05\right)$ and motivating-rewarding $\left(F_{5,378}=3.52, p<.05\right)$, but the coefficients on these terms did not follow the appropriate pattern for either model. These results provide only limited support for Hypothesis 3 , in that significant moderating effects for importance were found in predicting job dissatisfaction, but these effects did not follow the functional form of the optimal model (as predicted in Hypothesis 1) or the monotonic or asymptotic models.

For D-A fit using the monotonic model, the products of importance with $D$ and $A$ (i.e., $I D$ and $I A$ ) were jointly significant for planning-coordinating and motivating-rewarding predicting job dissatisfaction $\left(F_{2,356}=4.29\right.$ and $F_{2,355}=8.58$, both $p<.05$ ) and for motivating-rewarding predicting tension $\left(F_{2,350}=3.05, p<.05\right)$. However, the coefficients on the $I D$ and $I A$ terms did not follow the pattern corresponding to the monotonic model. For the optimal and asymptotic models, the set of terms multiplied by importance (i.e., $I D$, $I A, I D^{2}, I D A, I A^{2}$ ) was not significant in any of the six equations (all $p>.05$ ). These results fail to support Hypothesis 4.

\section{Follow-Up Analyses of Surfaces Relating Environment and Person to Strain}

The reported results indicate that, with the exception of the monotonic model for D-A fit predicting tension, none of the models shown in Figure 2 was supported. However, these models were highly constrained in that they presumed effects of equal magnitude for environment and person, allowed no 
change in strain along lines running parallel to the $E=P$ line, and precluded hybrid models that combine core aspects of the models in Figure 2. Variations such as these may be consistent with the fundamental processes underlying the monotonic, asymptotic, and optimal models and may also suggest other effects that are interpretable from the perspective of P-E fit theory.

To more fully examine the relationships of environment and person with strain in the present data, I conducted exploratory analyses supplemented by cross-validation. These analyses began with the creation of two random subsamples of equal size. For both subsamples, I estimated equations of progressively higher order (linear, quadratic, cubic, etc.), adding higher-order terms in sets and stopping when the increment in $R^{2}$ was no longer significant. From these analyses, a set of common equations was identified, consisting of the highest-order equations that emerged in both subsamples. This procedure yielded nine linear and three quadratic equations. For each equation, I tested differences in the coefficients from the two subsamples (Cohen \& Cohen, 1983: $312-317)$ to ensure that the equations for the subsamples were comparable (no significant differences were found, all $p>.05$ ). These equations were then reestimated with data from the full sample.

Of the nine linear equations, three contained $S$ and $V$ as predictors of tension (see Table 2). For planning-coordinating and decision making, the coefficient on $S$ was positive, indicating that tension rose as supplies increased. For motivating-rewarding, the coefficient on $S$ was positive and the coefficient on $V$ was negative, indicating that tension rose as supplies increased but fell as values increased. These relationships are the reverse of those corresponding to the monotonic model for $S-\mathrm{V}$ fit.

The remaining six linear equations contained $D$ and $A$ as predictors (see Table 3). For the equations predicting job dissatisfaction, the coefficients on $D$ and $A$ were both negative, indicating that dissatisfaction decreased as either demands or abilities increased. For the equations predicting tension, the coefficient on $D$ was positive and the coefficient on $A$ was negative. As noted previously, these coefficients differed in absolute magnitude for planning-coordinating and motivating-rewarding but not for decision making. Hence, the equation for decision making supported a strong version of the monotonic model, whereas the equations for planning-coordinating and motivating-rewarding supported a weak version of the monotonic model.

Because the nine linear equations contained only first-order terms, their interpretation was relatively straightforward. However, the three quadratic equations (i.e., $S, V, S^{2}, S V$, and $V^{2}$ as predictors of job dissatisfaction) were more difficult to interpret because they contained curvilinear and interactive terms with coefficients that did not conform to the optimal or asymptotic models. To interpret these equations, I applied the framework presented by Edwards and Parry (1993). This framework consists of analyzing three basic features of surfaces corresponding to quadratic equations. The first is the stationary point, or the point at which the slope of the surface is zero in all directions. The second consists of the first and second principal axes of the surface. For convex (i.e., bowl-shaped) surfaces, the upward curvature is 
greatest along the first principal axis and smallest along the second principle axis. For concave (i.e., dome-shaped) surfaces, the downward curvature is greatest along the second principal axis and smallest along the first principal axis. For saddle-shaped surfaces, the upward curvature is greatest along the first principal axis, and the downward curvature is greatest along the second principal axis. The third feature involves the slope of the surface along various lines of interest, such as the $S=V$ line (i.e., the line of "perfect" $S$ $\mathrm{V}$ fit), the $\mathrm{S}=-\mathrm{V}$ line (running perpendicular to the $S=V$ line), and the two principal axes.

Formulas provided by Edwards and Parry (1993) were used to calculate the stationary point, principal axes, and slopes along the $S=V$ line, $S=-V$ line, and principal axes of the surfaces corresponding to the three quadratic equations. I conducted significance tests by dividing the value from each formula by its standard error, using procedures described by Edwards and Parry. Supplemental analyses were conducted to determine whether the quantity $-\mathrm{p}_{20} /\left(1+\mathrm{p}_{21}\right)$ differed from zero (where $\mathrm{p}_{20}$ and $\mathrm{p}_{21}$ represent the intercept and slope of the second principal axis, respectively) and whether $\mathrm{p}_{21}$ differed from one. ${ }^{6}$ If the results of both tests were not significant, then the line along which strain was minimized did not differ from the $S=V$ line, as predicted by the optimal model (e.g., Figure 2e). If $\mathrm{p}_{21}$ differed from one, the second principal axis was rotated off the $S=V$ line, whereas if the quantity $-\mathrm{p}_{20} /\left(1+\mathrm{p}_{21}\right)$ differed from zero, the second principal axis intersected the $S=-V$ line at a point other than $S=0, V=0$, thereby representing a lateral shift along the $S=-V$ line.

Surfaces for the three quadratic equations were saddle-shaped (see Figure 3 [3a-3c]), with each second principal axis rotated slightly but not significantly off the $S=V$ line (all $p>.05$ ). The slope of each surface along the $S=-V$ line was curved upward $\left(\mathrm{a}_{\mathrm{s}^{2}}=0.073\right.$ for planning-coordinating; $\mathrm{a}_{\mathrm{s}^{2}}=$ 0.090 for decision making; $\mathrm{a}_{s^{2}}=0.061$ for motivating-rewarding, all $p<.05$ ) and flat at the point where $S=V\left(\mathrm{a}_{s}=-0.133\right.$ for planning-coordinating; $\mathrm{a}_{s}=$ -0.244 for decision making; $\mathrm{a}_{s}=-0.058$ for motivating-rewarding, all $p>$ $.05){ }^{7}$ Thus, along the $S=-V$ line, dissatisfaction was minimized at the point of perfect fit and increased in either direction, as predicted by Hypothesis 1. However, the slope along the $S=V$ line differed somewhat across the three surfaces. For planning-coordinating, the slope was negative and linear $\left(\mathrm{a}_{s}=\right.$ $-0.268, p<.05 ; \mathrm{a}_{\mathrm{s}^{2}}=-0.007, p>.05$ ), indicating that dissatisfaction was lower when supplies and values were both high than when both were low. For decision making, the slope along the $S=V$ line was curved downward

${ }^{6}$ The quantity $-\mathrm{p}_{20} /\left(1+\mathrm{p}_{21}\right)$ represents the point at which the second principal axis crosses the $S=-V$ line. When $S$ and $V$ are scale-centered, this quantity will equal zero when the second principal axis crosses the $S=-V$ line at the center of the $S, V$ plane, where the $S=V$ and $S=-V$ lines intersect.

${ }^{7}$ Following Edwards and Parry (1993), I represented the curvature of the surface along a given line running through the $S, V$ plane by $\mathrm{a}_{s^{2}}$ and the slope of the surface along the line at the point $S=O$ by $\mathrm{a}_{s}$. 


\section{FIGURE 3a}

\section{Planning-Coordinating Supplies, Values, and Dissatisfaction}

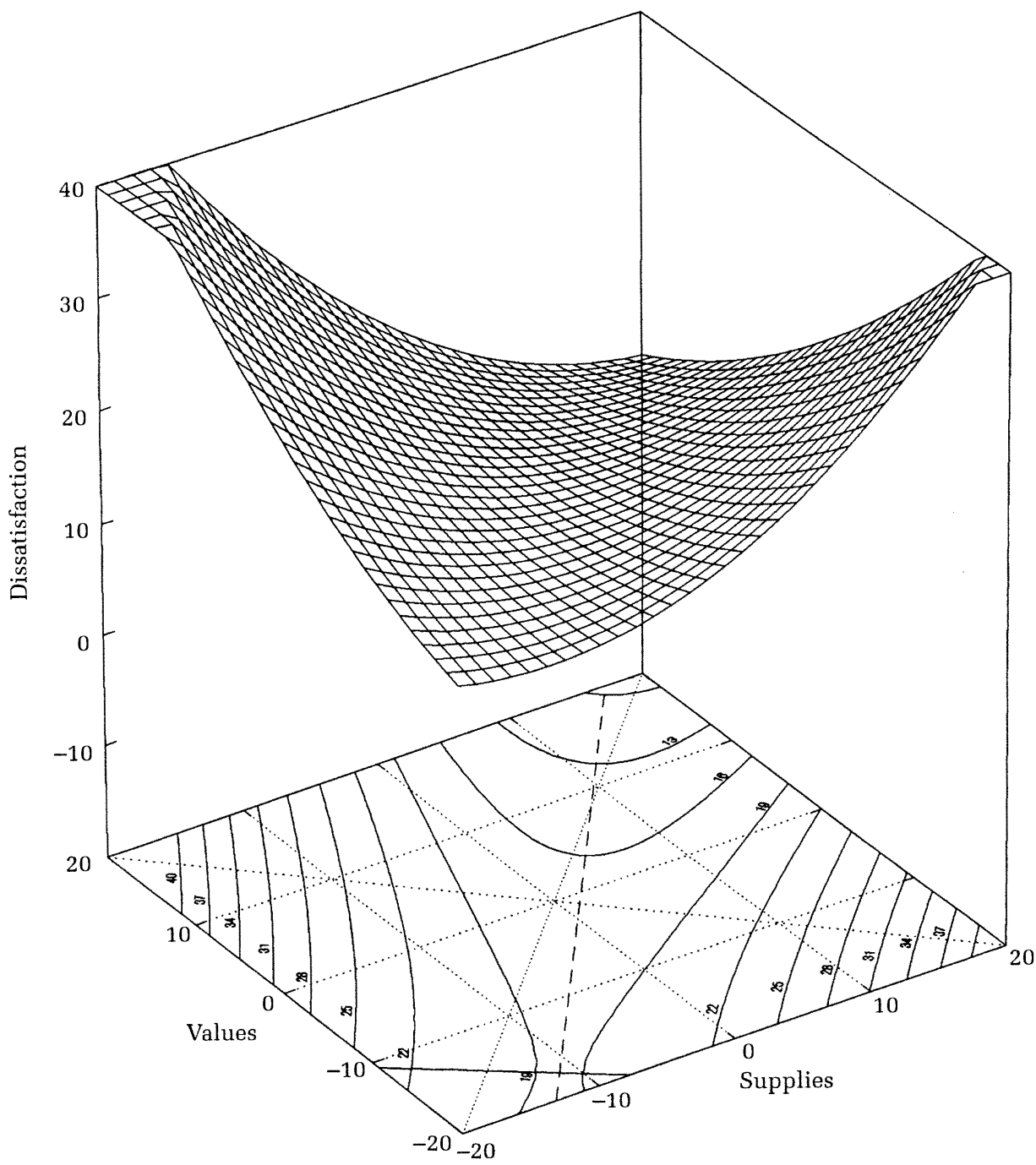

$\left(\mathrm{a}_{s}=-0.281, p>.05 ; \mathrm{a}_{s^{2}}=-0.022, p<.05\right)$, with its maximum at about the point $S=-6, V=-6$. However, no respondents scored below -6 on both $S$ and $V$, meaning that dissatisfaction decreased at an increasing rate along the $S=V$ line within the bounds of the data. For motivating-rewarding, the slope along the $S=V$ line was also curved downward $\left(\mathrm{a}_{s}=-0.254\right.$, $\mathrm{a}_{s^{2}}=-0.012$, both $p<.05$ ), with its maximum at about the point $S=-10$, $V=-10$. In contrast to the results for decision making, in these results 32 respondents scored below $\mathbf{- 1 0}$ on both $S$ and $V$, indicating that the decrease in dissatisfaction at low levels of supplies and values was within the bounds of the data. 


\section{FIGURE 3b}

\section{Decision-Making Supplies, Values, and Dissatisfaction}

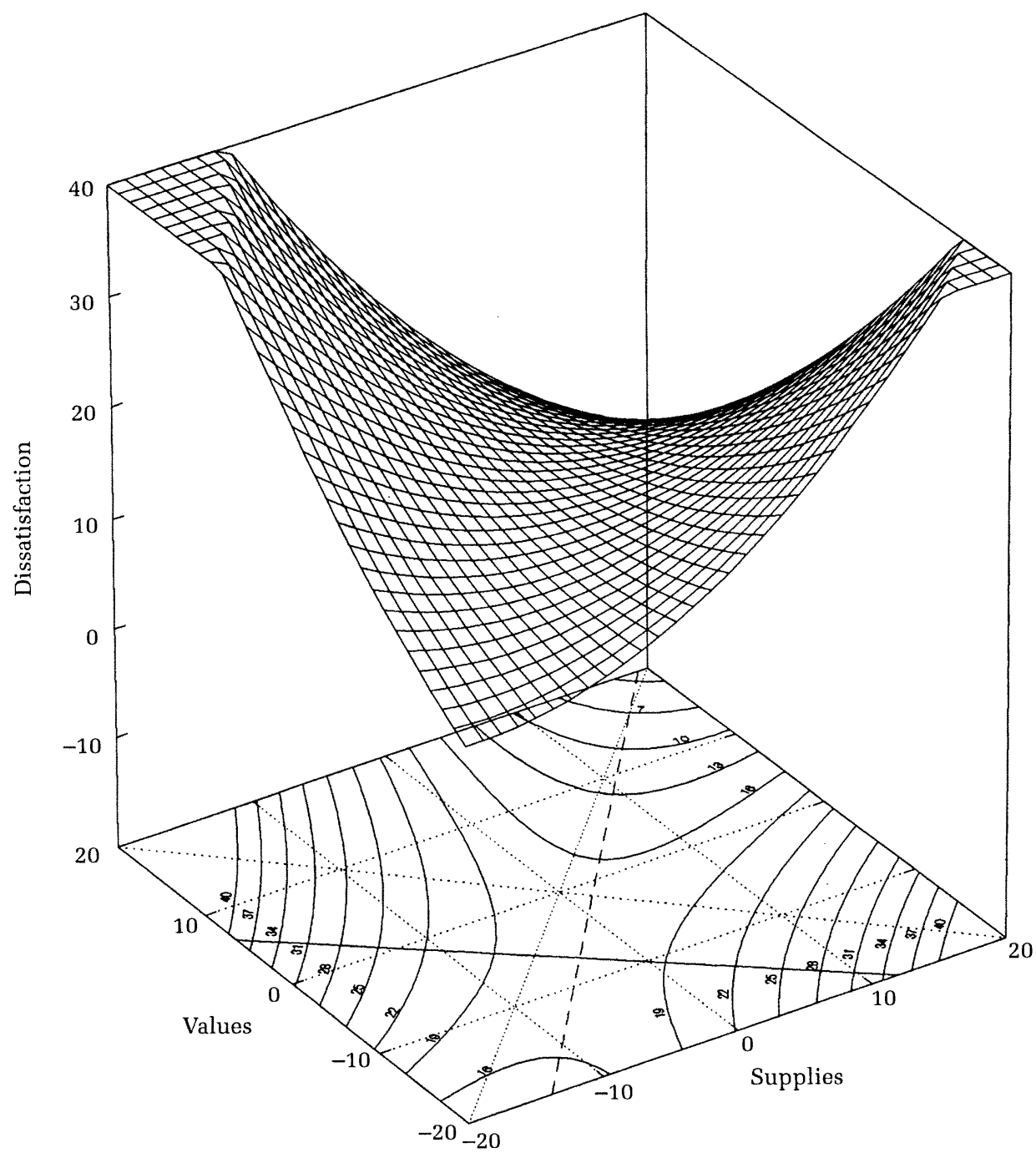

The moderating effects of importance were reexamined for the preceding equations. As noted earlier, significant effects were found for the linear equations containing $D$ and $A$ for planning-coordinating and motivatingrewarding predicting job dissatisfaction and for motivating-rewarding predicting tension. For all three equations, the coefficients on $I D$ and $I A$ were negative, but only the coefficient on $I A$ for motivating-rewarding predicting job dissatisfaction was significant $\left(b=-0.016, t_{355}=-2.87, p<.05\right)$. This coefficient indicated that the negative relationship between abilities and job dissatisfaction became more negative as importance increased. 


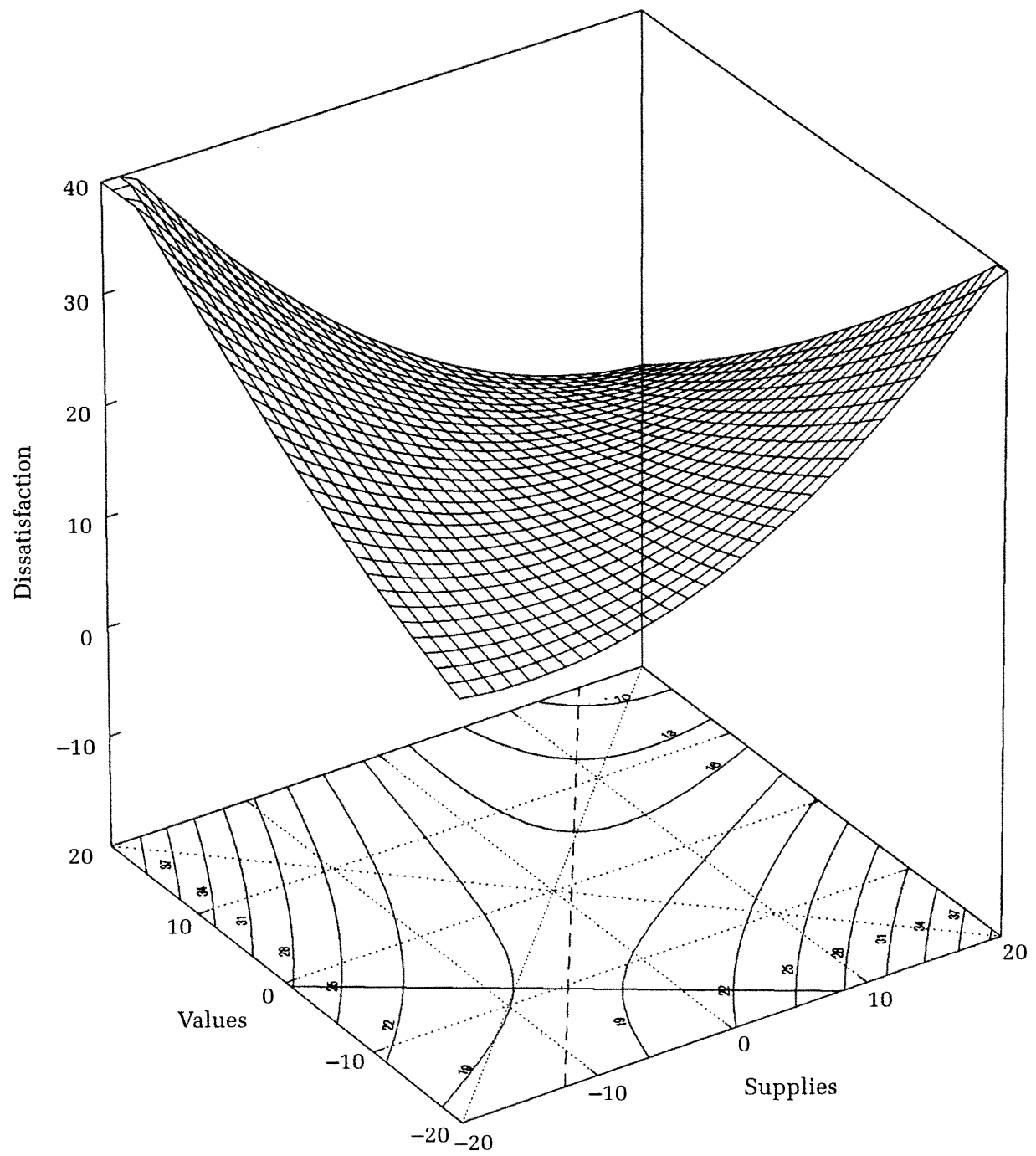

Significant moderating effects were also found for the quadratic equations containing $S, V, S^{2}, S V$, and $V^{2}$ for decision making and motivatingrewarding predicting job dissatisfaction, as reported earlier. To interpret these effects, I plotted surfaces at three levels of importance-the mean and one standard deviation above and below the mean (Cohen \& Cohen, 1983)-and tested slopes along the $S=V$ and $S=-V$ lines at each level of importance.

The surfaces for decision making and motivating-rewarding were similar at each level of importance (see Figure 4[4a-4f]). Specifically, when importance was low, both surfaces were flat along the $S=V$ line $\left(p>.05\right.$ for $\mathrm{a}_{s}$ 


\section{FIGURE 4a}

\section{Decision-Making Importance Low}

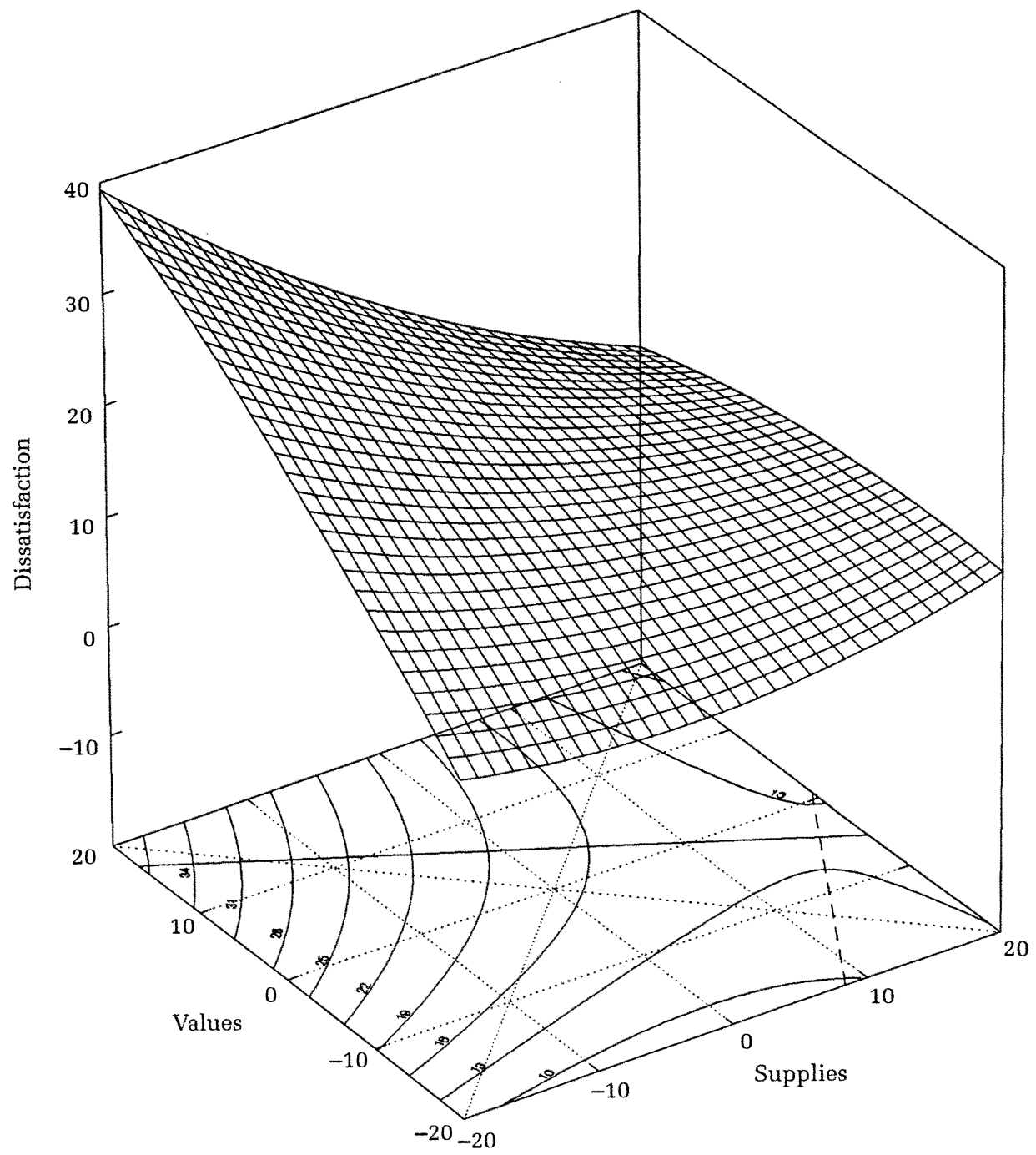

and $\mathrm{a}_{s^{2}}$ for both task dimensions) and negatively sloped along the $S=-V$ line $\left(\mathrm{a}_{s}=-0.684\right.$ for decision making; $\mathrm{a}_{s}=-0.742$ for motivating-rewarding, both $p<.05 ; p>.05$ for both $\mathrm{a}_{\mathrm{s}^{2}}$ ), indicating that dissatisfaction was greatest when values were high and supplies were low and decreased linearly as supplies increased and values decreased. When importance was at its mean, the surfaces were again flat along the $S=V$ line but curved upward along the $S=-V$ line $\left(\mathrm{a}_{s^{2}}=0.086\right.$ for decision making; $\mathrm{a}_{s^{2}}=0.053$ for motivatingrewarding, both $p<.05 ; p>.05$ for both $\mathrm{a}_{s}$ ), meaning that dissatisfaction was lowest when supplies and values were approximately equal and increased in either direction. When importance was high, the surfaces had a somewhat 


\section{FIGURE 4b}

\section{Motivating-Rewarding Importance Low}

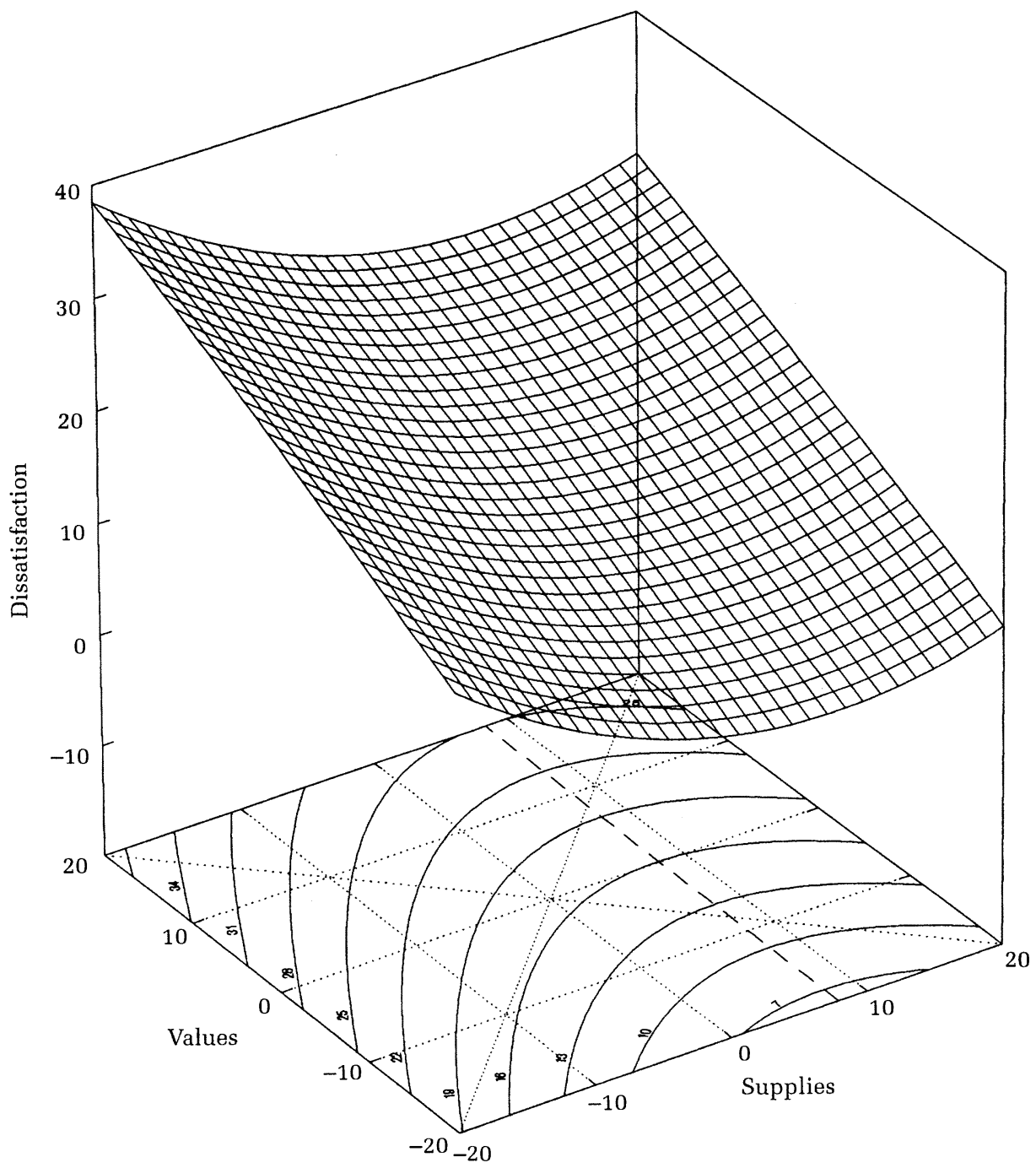

greater upward curvature along the $S=-V$ line $\left(\mathrm{a}_{s^{2}}=0.151\right.$ for decision making; $\mathrm{a}_{s^{2}}=0.089$ for motivating-rewarding, both $p<.05 ; p>.05$ for both $\left.\mathrm{a}_{s}\right)$, and were also negatively sloped along the $S=V$ line $\left(\mathrm{a}_{s}=-0.731\right.$ for decision making; $\mathrm{a}_{\mathrm{s}}=-0.314$ for motivating-rewarding, both $p<.05 ; p>$ .05 for both $\mathrm{a}_{s^{2}}$, so dissatisfaction not only increased as supplies deviated from values, but also increased as supplies and values decreased.

\section{Comparisons of S-V Fit and D-A Fit}

Two sets of analyses were conducted to compare the variance in strain explained by S-V and D-A fit. The first compared $R^{2}$ s from equations using 
FIGURE 4C

\section{Decision-Making Importance Medium}

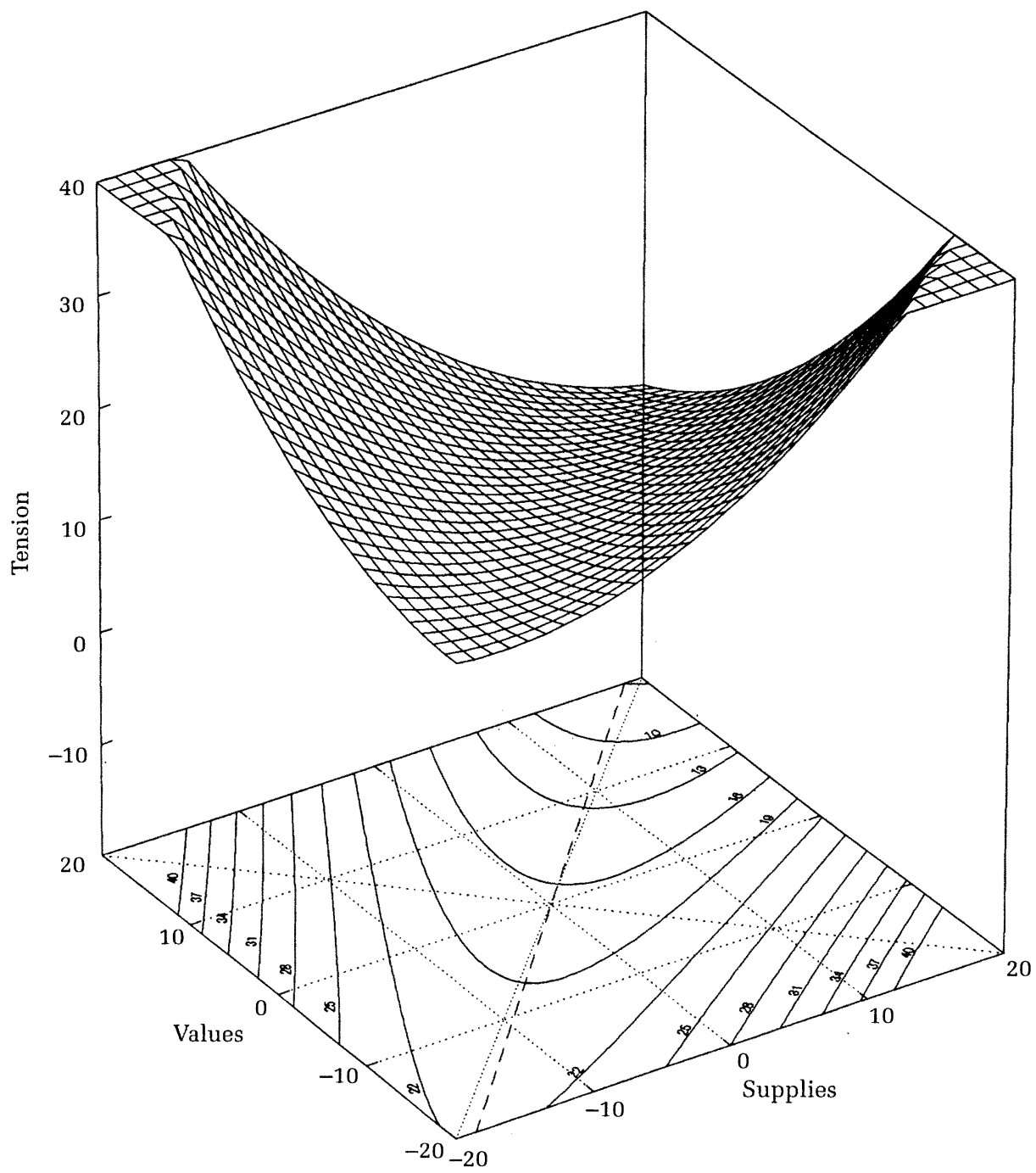

terms from either version of fit as predictors. Because the equations were not nested, the usual $F$-test was not appropriate. Therefore, I used the jackknife (Efron, 1982) to estimate the standard error of the difference in $R^{2}$ s. The second set of analyses tested the increment in $R^{2}$ when terms from one version of fit were entered after controlling for terms from the other version, using the standard $F$-test. All analyses used the linear and quadratic equations with and without the moderating effects of importance, based on a subsample with complete data on all measures $(n=326)$. This procedure held everything constant except the use of $S$ and $V$ versus $D$ and $A$ (and their associated 
FIGURE 4d

Motivating-Rewarding Importance Medium

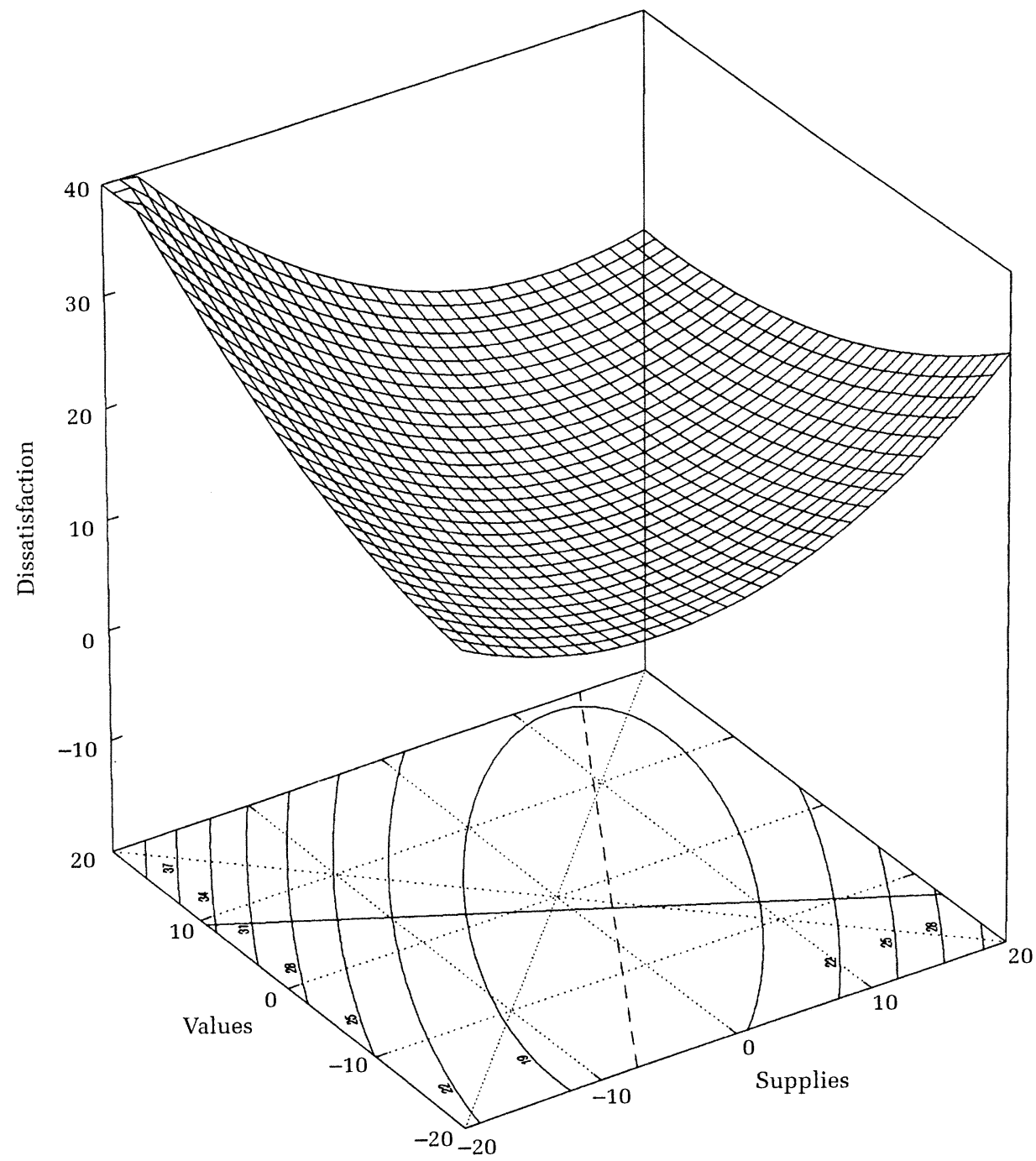

higher-order terms) as predictors. Probability levels for significance tests were corrected with the sequential Bonferroni procedure.

The results of these analyses followed a clear pattern (see Table 4). With job dissatisfaction as the dependent variable, the $R^{2}$ for $\mathrm{S}-\mathrm{V}$ fit was higher than that for D-A fit, with an average difference of .120. These differences were significant for both quadratic equations for motivating-rewarding and for all four equations for decision making. With tension as the dependent variable, the $R^{2}$ for D-A fit averaged .075 higher than that for $\mathrm{S}-\mathrm{V}$ fit, but these differences were significant only for the moderated linear equation. 
FIGURE 4e

\section{Decision-Making Importance High}

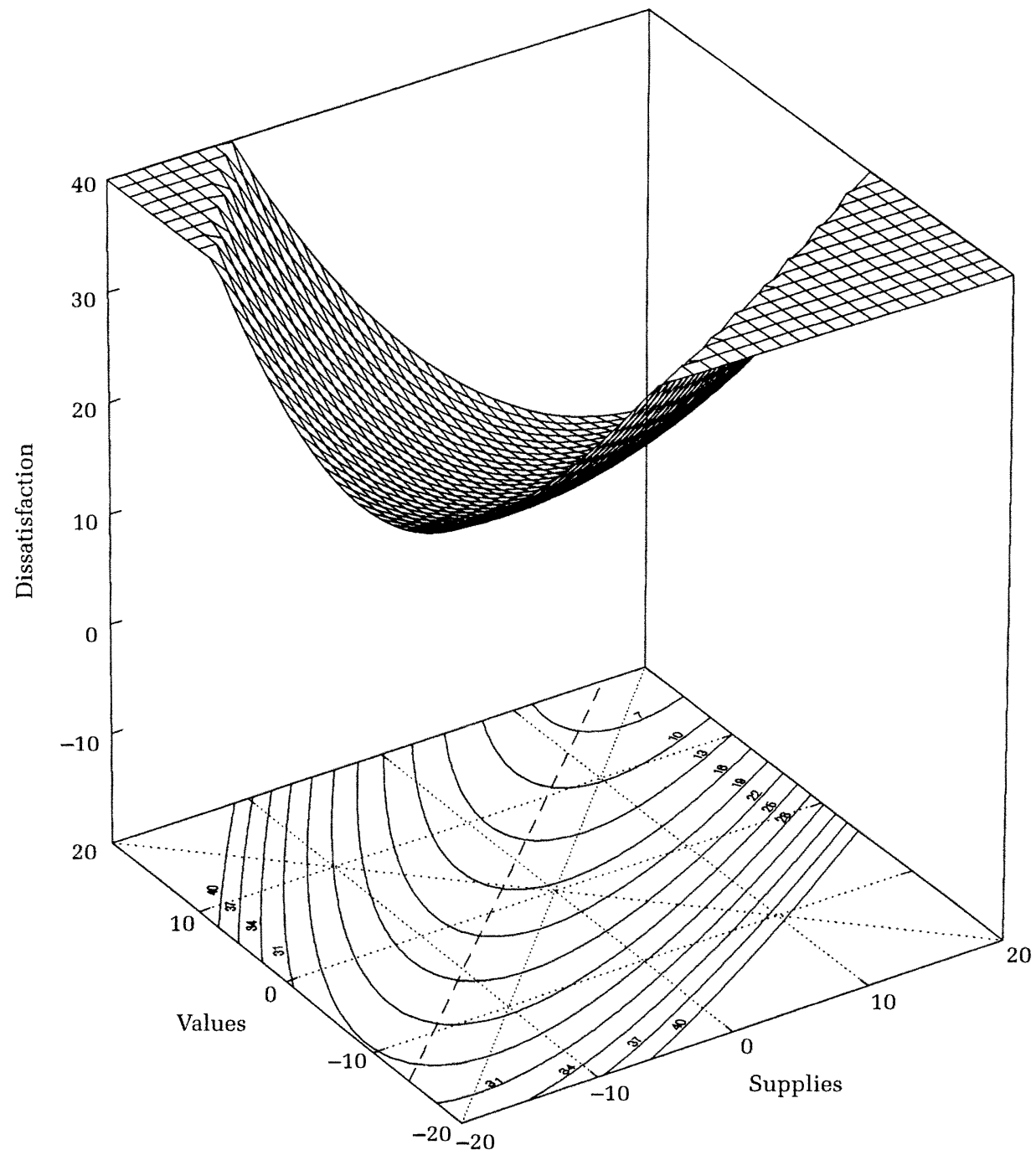

In the equations that excluded importance, the increment in $R^{2}$ for the $\mathrm{S}-\mathrm{V}$ fit terms after controlling for the D-A fit terms was significant for both job dissatisfaction and tension. In contrast, the increment in $R^{2}$ for the D-A fit terms was significant for job satisfaction only for planning-coordinating but was significant for tension for all three task dimensions. In the equations that included importance, the increment in $R^{2}$ for the $\mathrm{S}-\mathrm{V}$ fit terms was significant for job dissatisfaction but, with one exception, was not significant for tension, whereas the increment in $R^{2}$ for the D-A fit terms was significant for tension but, with one exception, was not significant for job dissatisfaction. Increments in $R^{2}$ for the S-V fit terms averaged .144 for job dissatisfaction 


\section{FIGURE 4f}

\section{Motivating-Rewarding Importance High}

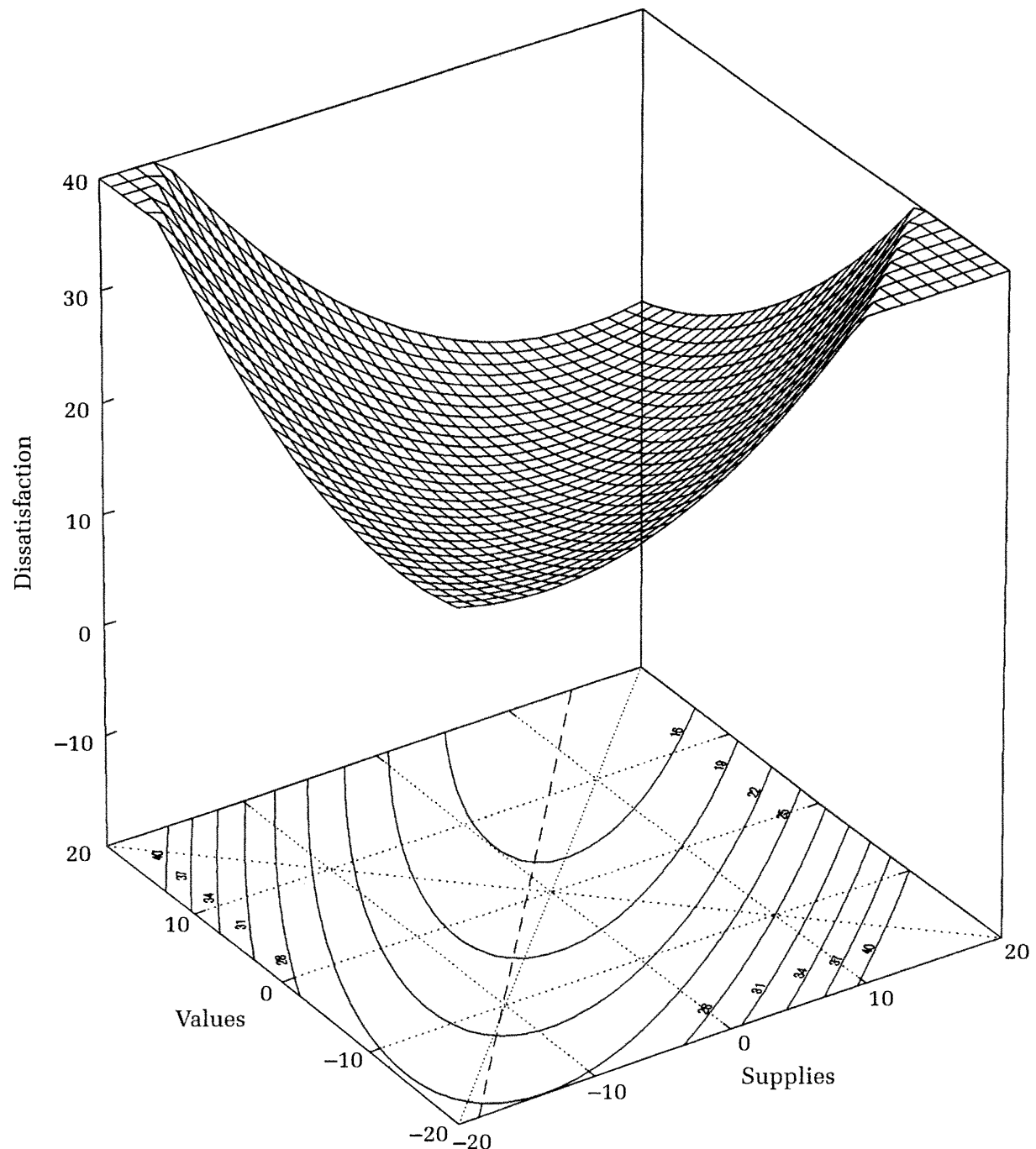

and .052 for tension, whereas increments in $R^{2}$ for the D-A fit terms averaged .025 for job dissatisfaction and .128 for tension. Overall, these results indicate that $\mathrm{S}-\mathrm{V}$ fit is superior to D-A fit in predicting job dissatisfaction, whereas $\mathrm{D}-\mathrm{A}$ fit is superior to $\mathrm{S}-\mathrm{V}$ fit in predicting tension. However, both versions of fit often explained variance in both job dissatisfaction and tension, particularly when the moderating effects of importance were excluded. These results support Hypothesis 5 for job dissatisfaction but contradict it for tension.

\section{DISCUSSION}

The results of this study indicate that the relationship of environment and person with strain combines certain aspects of the monotonic, asymp- 


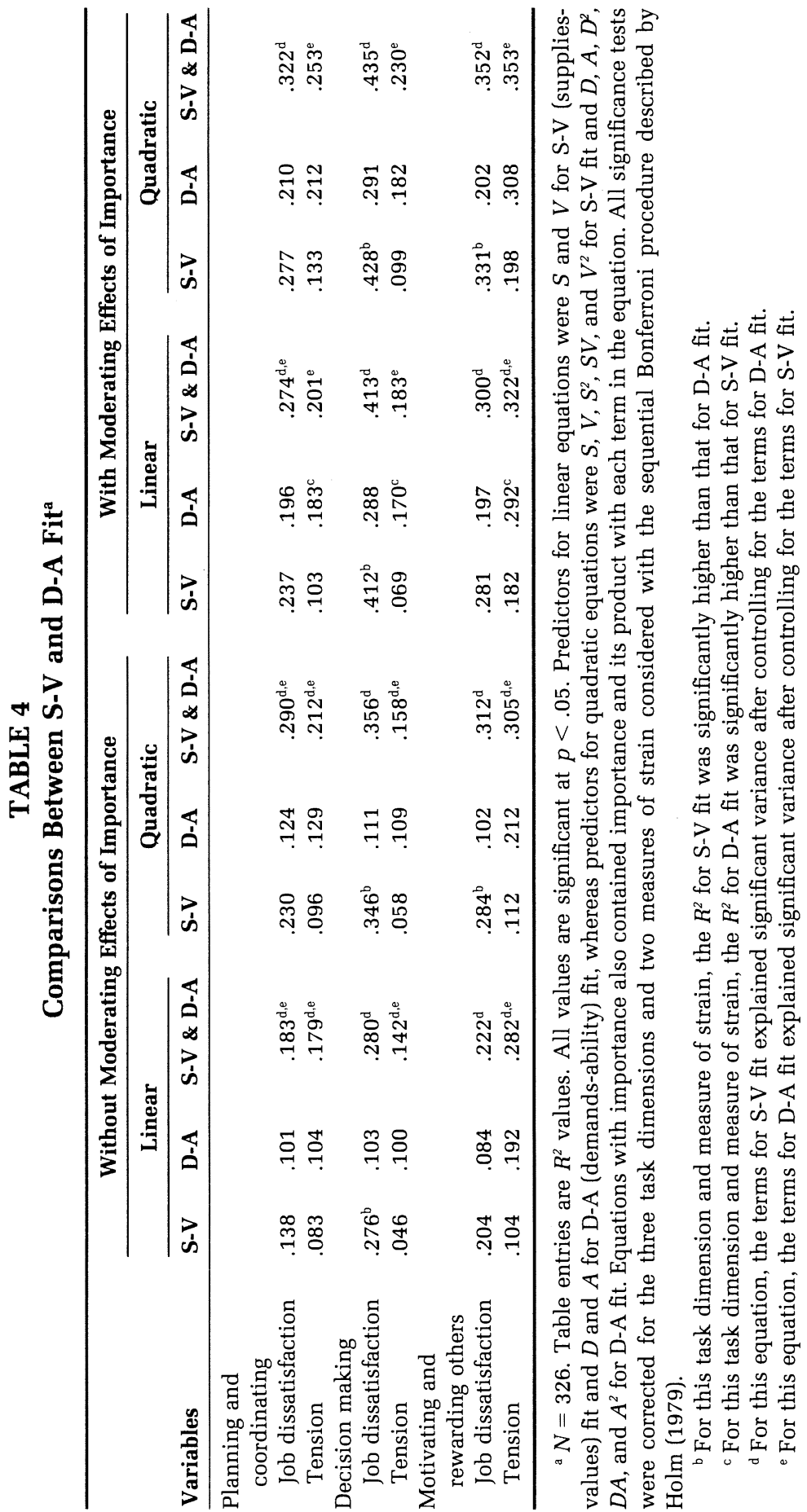


totic, and optimal models with other substantively meaningful effects. Specifically, for S-V fit, job dissatisfaction not only increased as supplies deviated from values (as predicted by Hypothesis 1), but was also higher when supplies and values were both low than when both were high. Edwards and Harrison (1993) obtained similar results for S-V fit on job complexity predicting boredom, job dissatisfaction, and workload dissatisfaction. Taken together, these findings support a modified version of the optimal model, in which strain increases not only when supplies and values differ, but also when they are both low in an absolute sense. The increase in strain for insufficient supplies corroborates a basic tenet of P-E fit theory, and the increase in strain for excess supplies suggests an interference effect, in which excess supplies on one dimension induce misfit on other dimensions. The drop in strain for high levels of supplies and values may reflect the cumulative effects of fit on multiple dimensions, in that high levels of the tasks examined here often bring such additional rewards as pay and status, and individuals who prefer high levels of these tasks may also value large amounts of these rewards (Harrison, 1978). Thus, S-V fit at high levels of supplies and values may represent a proxy for $\mathrm{S}-\mathrm{V}$ fit on other dimensions.

Unlike job dissatisfaction, tension was positively related to supplies and, to a lesser extent, negatively related to values. These relationships fail to support Hypothesis 1 and are the reverse of those associated with the monotonic model. Perhaps high supplies for the tasks considered here signify greater quantitative workload or responsibility for others, which may directly increase tension (French \& Caplan, 1972; Ganster \& Schaubroeck, 1991). High supplies may also require greater activity levels, which may heighten physiological arousal and thereby generate subjective manifestations of tension.

For D-A fit, job dissatisfaction decreased as demands and abilities increased. Although this finding deviates from the three models shown in Figure 2 (including that specified by Hypothesis 2), it corroborates Karasek's (1979) notion that demanding jobs coupled with high decision latitude (which represents a situational determinant of ability) enhance job satisfaction, perhaps by creating opportunities for people to use valued skills and demonstrate their competence (Locke, 1976; White, 1959). Such jobs are also more prevalent at higher organizational levels, which may provide intrinsic and extrinsic rewards that further reduce dissatisfaction. These two interpretations suggest a modified carryover effect, in which S-V fit on other dimensions results not from excess abilities, but rather from matching high abilities with high demands.

Finally, tension was positively related to demands and negatively related to abilities. Although this finding failed to support Hypothesis 2, it was consistent with the monotonic model. For decision making, demands and abilities exhibited equal but opposite relationships, supporting a strong version of the monotonic model, whereas for planning-coordinating and motivating-rewarding, demands exhibited a stronger relationship than abilities, supporting a weak version of the model. These findings suggest that the 
carryover effects of excess abilities outweighed the depletion and interference effects, resulting in a net decrease in tension. One explanation for these findings involves the passage of time. Specifically, excess abilities may have been immediately applied to other demands and produced concurrent reductions in tension, so that carryover occurred without delay. In contrast, excess abilities may not be depleted or interfere with values such as selfactualization unless considerable time has passed, perhaps more time than many respondents had been employed.

Importance moderated the relationship of $\mathrm{S}-\mathrm{V}$ fit with job dissatisfaction for decision making and motivating-rewarding, providing partial support for Hypothesis 3. When importance was low, dissatisfaction increased as supplies decreased or values increased, a pattern analogous to that of the monotonic model. When importance was moderate, dissatisfaction increased as supplies deviated from values, consistent with the optimal model. When importance was high, dissatisfaction not only increased as supplies deviated from values, but was also higher when supplies and values were both low than when both were high. These results suggest that, whereas insufficient supplies are related to dissatisfaction at all levels of importance, excess supplies are related to dissatisfaction only when importance is moderate or high. Perhaps excess task supplies signify overload, thereby inhibiting task performance, and more important tasks are given greater weight in evaluating job performance. If so, then excess task supplies would have greater negative consequences as task importance increases, as the present findings suggest. This indicates a contingent interference effect, with excess task supplies creating $\mathrm{S}-\mathrm{V}$ misfit on other dimensions (in this case, job performance) only for important tasks. The decrease in dissatisfaction along the $S=V$ line at high levels of importance suggests that the cumulative effects of fit on multiple dimensions implied by high supplies and values may be stronger for more important tasks, or perhaps that perceived importance increases when task supplies and values are linked to supplies and values on other dimensions. An alternative explanation for these findings is that unimportant tasks invoke a simplistic cognitive appraisal process, focusing merely on whether supplies fulfill values, whereas important tasks invoke a more complex appraisal process, focusing not only on whether supplies fulfill values, but also on the absolute levels of supplies and values (Beach \& Mitchell, 1978; Janis \& Mann, 1977).

A weak moderating effect for importance was found in the relationship between D-A fit and job dissatisfaction for motivating-rewarding, providing limited support for Hypothesis 4. Specifically, as importance increased, the negative relationship of dissatisfaction with abilities (and, to a lesser extent, demands) became increasingly negative. Perhaps the benefits of high demands and abilities are greater for tasks considered more important to one's overall job, particularly when those tasks involve responsibility for subordinates.

Comparisons of S-V and D-A fit indicated that, although both versions of fit were related to both forms of strain, S-V fit was more strongly associated 
with job dissatisfaction, whereas D-A fit was more strongly associated with tension. The former relationship supports Hypothesis 5, whereas the latter is contrary to Hypothesis 5. These apparently conflicting findings suggest that S-V and D-A fit are related to different forms of affect. Specifically, deviations of supplies from values may be primarily linked to displeasure, as reflected by job dissatisfaction in the work context (Diener, 1984; Locke, 1976; Rice et al., 1985). In contrast, demands that exceed abilities may invoke increased goal striving and effort expenditure, leading to sustained physiological arousal (Selye, 1956) and, in turn, subjective manifestations of tension. This reasoning suggests that $\mathrm{S}-\mathrm{V}$ and $\mathrm{D}-\mathrm{A}$ fit may be respectively linked to the pleasure-displeasure and arousal dimensions of the circumplex model of affect (Russell, 1980; Watson \& Tellegen, 1985).

Although this study has yielded several important findings regarding the P-E fit approach to stress, it has several limitations. For example, the data were cross-sectional, which hinders causal inferences regarding the relationship between fit and strain. Although unlikely, it is possible that respondents who experienced greater strain subsequently created or perceived work environments with greater misfit. Also, respondents were relatively young and had limited work experience, conditions that limit generalizations to the broader working population. In addition, a retrospective design was used, which may have created errors in recall. However, such errors are unlikely, given that data were collected very shortly after respondents left their jobs. Furthermore, sample sizes for the exploratory analyses were modest ( $N$ ranged from 189 to 211), which limited statistical power and may have favored models with fewer higher-order terms.

Other shortcomings involve the measures used. For example, because fully commensurate environment, person, and strain measures were not available, I designed new measures for this study. Use of the new measures limits the correspondence between this study and the existing stress literature and yielded measures with certain psychometric drawbacks (e.g., low reliabilities for processing paperwork and exchanging information, high correlations between measures of planning-coordinating and motivating-rewarding). In addition, these measures focused on a limited set of tasks, thereby excluding other potentially relevant job dimensions. Finally, all measures used self-report data. This approach is consistent with P-E fit theory, whose proponents argue that strain results from perceived rather than objective misfit (French et al., 1982). However, it undoubtedly introduced common method variance, inflating the correlations among the environment, person, and strain measures (Podsakoff \& Organ, 1986; Williams \& Brown, 1994). This inflation probably had little effect on tests of the monotonic, asymptotic, and optimal models or comparisons of S-V and D-A fit, because these analyses focused on alternative specifications of $\mathrm{P}-\mathrm{E}$ fit rather than the absolute magnitudes of relationships among environment, person, and strain. Moreover, common method variance is unlikely to induce nonlinear and interactive relationships such as those found here (Evans, 1985). Nonetheless, the shortcomings of these measures merit attention, and it would be worthwhile 
to replicate this study by adapting existing measures, examining other job dimensions, and employing multiple methods.

Despite these limitations, the present study suggests several potentially fruitful directions for future P-E fit research. For example, the increase in dissatisfaction as supplies deviated from values suggests that excess supplies interfere with $\mathrm{S}-\mathrm{V}$ fit on other dimensions. These effects could be tested by measuring supplies and values on instrumentally related dimensions and examining whether S-V misfit increases on one dimension as supplies exceed values on other dimensions. Moreover, dimensions other than task activities should be measured to determine whether interference and carryover effects vary according to the content of the dimensions along which $\mathrm{S}-\mathrm{V}$ fit is assessed. Furthermore, as noted earlier, the reduction in job dissatisfaction with increased supplies and values may reflect the cumulative effects of $\mathrm{S}-\mathrm{V}$ fit on multiple dimensions. A researcher could investigate this possibility by controlling for fit on these dimensions and examining whether the negative relationship of supplies and values with dissatisfaction was reduced.

The results of this study also raise questions for future research into D-A fit. For example, the positive relationship between supplies and tension suggests the operation of two versions of D-A fit, one representing qualitative workload (as reflected by supplies), and another representing quantitative workload (French et al., 1982). Future studies may include measures of both qualitative and quantitative D-A fit in reference to the same task dimensions to examine their relative effects on strain. Furthermore, the decrease in dissatisfaction at high levels of demands and abilities implies a carryover effect between D-A fit on task activities and S-V fit on intrinsic and extrinsic rewards. Examining this possibility would require measuring D-A and S-V fit in reference to task and reward dimensions, respectively, and testing whether S-V fit mediates the effects of D-A fit on strain.

The relative effects of $S-V$ and D-A fit also merit further investigation. For example, the present study suggests that S-V and D-A fit may be linked to pleasure and arousal, respectively. Researchers could examine this link by using measures of emotions that comprehensively cover the bipolar affective space defined by these dimensions (Russell, 1980; Watson \& Tellegen, 1985). Also, the finding that D-A fit was related to strain after S-V fit was controlled challenges the assumption that D-A misfit impacts strain only through S-V misfit (French et al., 1982; Harrison, 1978, 1985). However, these findings were limited to S-V and D-A fit within the same taxonomic domain, which does not preclude the possibility that D-A misfit affects strain by creating S$\mathrm{V}$ misfit on distinct but instrumentally related dimensions, as when excess job demands inhibit performance and thus prevent the attainment of valued intrinsic and extrinsic rewards. Researchers could investigate this possibility by using measures of S-V and D-A fit on these dimensions and examining their relationships within a comprehensive structural model.

Finally, the causal relationships specified by carryover and interference and the temporal effects represented by conversation and depletion require measuring supplies, values, demands, abilities, and strain over time. There- 
fore, longitudinal research should be conducted to determine whether these processes underlie the various functional forms relating S-V and D-A fit to strain.

\section{CONCLUSION}

This study compared the S-V and D-A versions of the P-E fit approach to stress and tested various functional forms relating both versions of fit to strain. Although S-V fit was linked primarily to dissatisfaction and D-A fit was linked primarily to tension, both versions of fit were related to both forms of strain. Also, the relationships of S-V and D-A fit with strain deviated from the simple two-dimensional functions typically examined in P-E fit research, but they nonetheless combined certain aspects of these functions with other conceptually meaningful effects, many of which suggest relationships between S-V and D-A fit on multiple dimensions. Future research should examine the joint effects of S-V and D-A fit on various indexes of strain and the relationships between S-V and D-A fit, thereby further illuminating the processes underlying the P-E fit approach to stress.

\section{REFERENCES}

Aiken, L. A., \& West, S. G. 1991. Multiple regression: Testing and interpreting interactions. Newbury Park, CA: Sage.

Bagozzi, R. P., \& Phillips, L. W. 1982. Representing and testing organizational theories: A holistic construal. Administrative Science Quarterly, 27: 459-489.

Beach, L. R., \& Mitchell, T. R. 1978. A contingency model for the selection of decision strategies. Academy of Management Review, 3: 439-449.

Beehr, T. A., \& Newman, J. E. 1978. Job stress, employee health, and organizational effectiveness: A facet analysis, model and literature review. Personnel Psychology, 31: 665699.

Belsley, D. A., Kuh, E., \& Welsch, R. E. 1980. Regression diagnostics: Identifying influential data and sources of collinearity. New York: Wiley.

Bollen, K. A., \& Jackman, R. W. 1990. Regression diagnostics: An expository treatment of outliers and influential cases. In J. Fox \& J. S. Long (Eds.), Modern methods of data analysis: 257-291. Newbury Park, CA: Sage.

Caplan, R. D. 1987. Person-environment fit theory and organizations: Commensurate dimensions, time perspectives, and mechanisms. Journal of Vocational Behavior, 31: 248267.

Cattell, R. B. 1966. The scree test for the number of factors. Multivariate Behavioral Research, 1: 946-976.

Chatman, J. A. 1989. Improving interactional organizational research: A model of person-organization fit. Academy of Management Review, 14: 333-349.

Cohen, J. 1988. Statistical power analysis for the behavioral sciences (2d ed.). New York: Academic Press.

Cohen, J., \& Cohen, P. 1983. Applied multiple regression/correlation analysis for the behavioral sciences $(2 \mathrm{~d}$ ed.). Hillsdale, $\mathrm{NJ}$ : Erlbaum.

Cooper, C. L., \& Marshall, J. 1976. Occupational sources of stress: Review of literature relating to coronary heart disease and mental ill health. Journal of Occupational Psychology, 49: $11-28$. 
Cronbach, L. J., \& Furby, L. 1970. How we should measure "change”-Or should we? Psychological Bulletin, 74: 68-80.

Cummings, T. G., \& Cooper, C. L. 1979. Cybernetic framework for studying occupational stress. Human Relations, 32: 395-418.

Dawis, R. V., \& Lofquist, L. H. 1984. A psychological theory of work adjustment. Minneapolis: University of Minnesota Press.

Diener, E. 1984. Subjective well-being. Psychological Bulletin, 95: 542-575.

Edwards, J. R. 1991. Person-job fit: A conceptual integration, literature review, and methodological critique. In C. L. Cooper \& I. T. Robertson (Eds.), International review of industrial and organizational psychology, vol. 6: 283-357. New York: Wiley.

Edwards, J. R. 1992. A cybernetic theory of stress, coping, and well-being in organizations. Academy of Management Review, 17: 238-274.

Edwards, J. R. 1994. The study of congruence in organizational behavior research: Critique and a proposed alternative. Organizational Behavior and Human Decision Processes, 58: 51-100 (erratum, 58: 323-325).

Edwards, J. R., \& Cooper, C. L. 1990. The person-environment fit approach to stress: Recurring problems and some suggested solutions. Journal of Organizational Behavior, 10: 293307.

Edwards, J. R., \& Harrison, R. V. 1993. Job demands and worker health: Three-dimensional reexamination of the relationship between person-environment fit and strain. Journal of Applied Psychology, 78: 628-648.

Edwards, J. R., \& Parry, M. E. 1993. On the use of polynomial regression equations as an alternative to difference scores in organizational research. Academy of Management Journal, 36: 1577-1613.

Efron, B. 1982. The jackknife, the bootstrap, and other resampling plans. Philadelphia: Society for Industrial and Applied Math.

Eulberg, J. R., Weekley, J. A., \& Bhagat, R. S. 1988. Models of stress in organizational research: A metatheoretical perspective. Human Relations, 41: 331-350.

Evans, M. G. 1985. A Monte Carlo study of the effects of correlated method variance in moderated multiple regression analysis. Organizational Behavior and Human Decision Process, 36: 305-323.

Fox, J. 1991. Regression diagnostics: An introduction. Newbury Park, CA: Sage.

French, J. R. P., Jr., \& Caplan, R. D. 1972. Organizational stress and individual strain. In A. J. Marrow (Ed.), The failure of success: 30-66. New York: Amacon.

French, J. R. P., Jr., Caplan, R. D., \& Harrison, R. V. 1982. The mechanisms of job stress and strain. New York: Wiley.

Ganster, D. C., \& Schaubroeck, J. 1991. Work stress and employee health. Journal of Management, 17: 235-271.

Hackman, J. R., \& Oldham, G. R. 1980. Work redesign. Reading, MA: Addison-Wesley.

Hall, D. T., \& Mansfield, R. 1971. Organizational and individual response to external stress. Administrative Science Quarterly, 16: 533-547.

Harrison, R. V. 1978. Person-environment fit and job stress. In C. L. Cooper \& R. Payne (Eds.), Stress at work: 175-205. New York: Wiley.

Harrison, R. V. 1985. The person-environment fit model and the study of job stress. In T. A. Beehr \& R. S. Bhagat (Eds.), Human stress and cognition in organizations: 23-55. New York: Wiley. 
Hesketh, B., \& Gardner, D. 1993. Person-environment fit models: A reconceptualization and empirical test. Journal of Vocational Behavior, 42: 315-332.

Hochberg, Y., \& Tamhane, A. C. 1987. Multiple comparison procedures. New York: Wiley.

Holland, J. L. 1985. Making vocational choices (2nd ed.). Englewood Cliffs, NJ: PrenticeHall.

Holm, S. 1979. A simple sequentially rejective multiple test procedure. Scandinavian Journal of Statistics, 6: 65-70.

House, R. J. 1988. Power and personality in complex organizations. In B. M. Staw \& L. L. Cummings (Eds.), Research in organizational behavior, vol. 10: 305-357. Greenwich, CT: JAI Press.

Irving, P. G., \& Meyer, J. P. 1994. Reexamination of the met-expectations hypothesis: A longitudinal analysis. Journal of Applied Psychology, 79: 937-949.

Ivancevich, J. M., \& Matteson, M. T. 1980. Stress and work. Glenview, IL: Scott, Foresman.

Jaccard, J., Turrisi, R., \& Wan, C. K. 1990. Interaction effects in multiple regression. Newbury Park, CA: Sage.

Jackson, S. E., \& Schuler, R. S. 1985. A meta-analysis and conceptual critique of research on role ambiguity and role conflict in work settings. Organizational Behavior and Human Decision Processes, 36: 16-78.

Janis, I. L., \& Mann, L. 1977. Decision making. New York: Free Press.

Johns, G. 1981. Difference score measures of organizational behavior variables: A critique. Organizational Behavior and Human Performance, 27: 443-463.

Joyce, W. Slocum, J. W., Jr., \& Von Glinow, M. A. 1982. Person-situation interaction: Competing models of fit. Journal of Occupational Behavior, 3: 265-280.

Kahn, R. L., \& Byosiere, D. 1990. Stress in organizations. In M. D. Dunnette \& L. M. Hough (Eds.), Handbook of industrial and organizational psychology (2nd ed.), vol. 3: 581-650. Palo Alto, CA: Consulting Psychologists Press.

Kalleberg, A. L. 1977. Work values and job rewards: A theory of job satisfaction. American Sociological Review, 42: 124-143.

Karasek, R. A., Jr. 1979. Job demands, job decision latitude, and mental strain: Implications for job redesign. Administrative Science Quarterly, 24: 285-308.

Kulik, C. T., Oldham, G. R., \& Hackman, J. R. 1987. Work design as an approach to personenvironment fit. Journal of Vocational Behavior, 31: 278-296.

Kulka, R. A. 1979. Interaction as person-environment fit. In L. R. Kahle (Ed.), New directions for methodology of behavioral science: 55-71. San Francisco: Jossey-Bass.

Lazarus, R. S., \& Folkman, S. 1984. Stress, coping, and adaptation. New York: Springer.

Lewin, K. 1951. Field theory in social science. New York: Harper.

Little, B. R. 1983. Personal projects: A rationale and method for investigation. Environment and Behavior, 15: 273-309.

Locke, E. A. 1976. The nature and causes of job satisfaction. In M. Dunnette (Ed.), Handbook of industrial and organizational psychology: 1297-1350. Chicago: Rand McNally.

Luthans, F., \& Lockwood, D. L. 1984. Toward an observation system for measuring leader behavior in natural settings. In J. G. Hunt, D. Hosking, C. Schriesheim, \& R. Stewart (Eds.), Leaders and managers: International perspectives on managerial behavior and leadership: 117-141. New York: Permagon Press.

Matteson, M. T., \& Ivancevich, J. M. 1979. Organizational stressors and heart disease: A research model. Academy of Management Review, 4: 347-357. 
McGrath, J. E. 1970. A conceptual formulation for research on stress. In J. E. McGrath (Ed.), Social and psychological factors in stress: 10-21. New York: Holt, Rinehart \& Winston.

McGrath, J. E. 1976. Stress and behavior in organizations. In M. Dunnette (Ed.), Handbook of industrial and organizational psychology: 1351-1395. Chicago: Rand McNally.

Miller, R. G., Jr. 1981. Simultaneous statistical inference (2nd ed.). New York: SpringerVerlag.

Murray, H. A. 1938. Explorations in personality. Boston: Houghton Mifflin.

Nunnally, J. C. 1978. Psychometric theory. New York: McGraw-Hill.

Parker, D. F., \& DeCotiis, T. A. 1983. Organizational determinants of job stress. Organizational Behavior and Human Performance, 32: 160-177.

Pervin, L. A. 1989. Persons, situations, interactions: The history of a controversy and a discussion of theoretical models. Academy of Management Review, 14: 350-360.

Podsakoff, P. M., \& Organ, D. W. 1986. Self-reports in organizational research: Problems and prospects. Journal of Management, 12: 531-544.

Rice, R. W., McFarlin, D. B., Hunt, R. G., \& Near, J. P. 1985. Organizational work and the perceived quality of life: Toward a conceptual model. Academy of Management Review, 10: 296-310.

Russell, J. A. 1980. A circumplex model of affect. Journal of Personality and Social Psychology, 39: 1161-1178.

Schein, E. 1978. Career dynamics: Matching individual and organizational needs. Reading, MA: Addison-Wesley.

Schneider, B., \& Schmitt, N. 1992. Staffing organizations. Prospect Heights, IL: Waveland Press.

Schuler, R. S. 1980. Definition and conceptualization of stress in organizations. Organizational Behavior and Human Performance, 25: 184-215.

Seaman, M. A., Levin, J. R., \& Serlin, R. C. 1991. New developments in pairwise multiple comparisons: Some powerful and practicable procedures. Psychological Bulletin, 110: $577-586$.

Sells, S. B. 1970. On the nature of stress. In J. E. McGrath (Ed.), Social and psychological factors in stress: 134-139. New York: Holt, Rinehart \& Winston.

Selye, H. 1956. The stress of life. New York: McGraw-Hill.

Shirom, A. 1982. What is organizational stress? A facet analytic conceptualization. Journal of Occupational Behavior, 3: 21-37.

Spokane, A. R. 1985. A review of research on person-environment congruence in Holland's theory of careers. Journal of Vocational Behavior, 26: 306-343.

Wall, T. D., \& Payne, R. 1973. Are deficiency scores deficient? Journal of Applied Psychology, 58: $322-326$.

Wanous, J. P. 1980. Organizational entry: Recruitment, selection, and socialization of newcomers. Reading, MA: Addison-Wesley.

Warr, P. B. 1990. Decision latitude, job demands, and employee well-being. Work $\&$ Stress, 4: 285-294.

Watson, D., \& Tellegen, A. 1985. Toward a consensual structure of mood. Psychological Bulletin, 98: 219-235.

White, R. W. 1959. Motivation reconsidered: The concept of competence. Psychological Review, 66: $297-333$. 
Williams, L. J., \& Brown, B. K. 1994. Method variance in organizational behavior and human resources research: Effects on correlations, path coefficients, and hypothesis testing. Organizational Behavior and Human Decision Process, 57: 185-209.

Jeffrey R. Edwards is an associate professor of organizational behavior and human resource management at the University of Michigan Business School. He earned his Ph.D. degree at the Graduate School of Industrial Administration at Carnegie Mellon University. His current research interests include stress, coping, and well-being in organizations, person-environment fit, work and nonwork values, measurement and construct validation, and methodological issues in congruence research. 